\title{
A comparative study on the reactive compatibilization of melt-processed polyamide 1010/polylactide blends by multi-functionalized additives derived from linseed oil and petroleum
}

\author{
L. Quiles-Carrillo ${ }^{1}$, O. Fenollar ${ }^{1}$, R. Balart ${ }^{1}$, S. Torres-Giner ${ }^{2}$, M. Rallini ${ }^{3}$, F. Dominici $^{3}$, L. Torre $^{3}$ \\ ${ }^{1}$ Technological Institute of Materials (ITM), Universitat Politècnica de València (UPV), Plaza Ferrándiz y Carbonell 1, \\ 03801 Alcoy, Spain \\ ${ }^{2}$ Novel Materials and Nanotechnology Group, Institute of Agrochemistry and Food Technology (IATA), Spanish National \\ Research Council (CSIC), Calle Catedrático Agustín Escardino Benlloch 7, 46980 Paterna, Spain \\ ${ }^{3}$ Dipartimento di Ingegneria Civile ed Ambientale, University of Perugia, UdR INSTM, Strada di Pentima, 4-05100 Terni, \\ Italy
}

Received 2 September 2019; accepted in revised form 21 October 2019

\begin{abstract}
This research work describes the manufacturing and characterization of novel engineering materials consisted of fully bio-based blends of polyamide 1010 (PA1010) with $20 \mathrm{wt} \%$ of polylactide (PLA). Four different compatibilizers were used to enhance the miscibility and the performance of the biopolymer blends. Two multi-functionalized vegetable oils (maleinized linseed oil (MLO) and epoxidized linseed oil (ELO)) and two petroleum-derived glycidyl-based additives (epoxy styrene-acrylic oligomer (ESAO) and styrene-glycidyl methacrylate copolymer (PS-GMA)) were tested during melt compounding. The resultant biopolymer blends were processed by either cast film extrusion or injection molding to obtain films and pieces, respectively. Thin films with an average thickness of 50-60 $\mu \mathrm{m}$ and thick pieces of $4 \mathrm{~mm}$ were obtained, and their mechanical, morphological, thermal, thermomechanical, barrier and, optical properties were characterized. Although all four compatibilizers successfully provided compatibilization to the blends, the chemically modified vegetable oils, that is, MLO and ELO yielded the injection-molded pieces with the most balanced mechanical properties in terms of strength and toughness. Besides, the resultant films showed very low oxygen transmission rate values, thus broadening the potential of these biopolymer blends for the food packaging industry.
\end{abstract}

Keywords: biopolymers, biocomposites, bio-based polyamides, multi-functionalized vegetable oils, reactive compatibilization

\section{Introduction}

The increasing awareness about sustainable development, petroleum depletion, carbon footprint, and so on, have recently been consolidated as the leading forces for the development of environmentally friendly materials [1]. For this reason, the plastic industry is every day more concerned about this issue, and bio-based and/or biodegradable polymers are gaining interest. This transition is not only affecting commodity plastics, but also engineering polymers. Aliphatic polyamides (PAs), also known as nylons, have received considerable attention in the last years since they can be fully or partially biobased and can offer similar properties to conventional petroleumderived PAs such as polyamide 6 (PA6) or polyamide 66 (PA66), representative for rigid uses or polyamide 12 (PA12) for flexible applications [2]. Today, some recent developments have been successful 
both from technical and economic standpoints to obtain sebacic acid from castor oil (CO). Sebacic acid, a $\mathrm{C} 10$ dicarboxylic acid, can readily react by conventional polycondensation with 1,10-decamethylene diamine (DMDA). DMDA can be bio-sourced through the exposure of sebacic acid to ammonia and, subsequently, subjected to dehydration and hydrogenation process, thus leading to fully bio-based polyamide 1010 (PA1010) [3]. PA1010 shows a relatively low melting temperature $\left(T_{\mathrm{m}}\right)$ compared to other PAs, and it can be used in engineering applications, which require high resistance (mechanical and chemical) such as fuel lines for cars, bike tubes, cable coating, tubes for high-temperature fluids, among others [4]. The long alkyl chains of PA1010 are responsible for low water absorption and, therefore, their mechanical properties are less sensitive to moisture [5]. Bio-based polyamides (bioPAs) are being introduced slowly in the packaging industry due to their cost and some technical restrictions. Despite this, some amorphous polyamides (aPA) have been reported, together with ethylene-vinyl alcohol copolymer (EVOH), as interesting films in multilayer systems intended for oxygen-sensitive food packages [6].

Polymer blending is one of the most cost-effective ways to obtain tailored properties that individual polymer cannot achieve [7]. The increasing availability of bio-based polymers and, particularly, polylactide (PLA) due to an excellent combination of processability, cost, and overall properties, represent interesting alternatives to high environmentally friendly polymer blends with improved properties [8,9]. PLA owns a privileged position in the bio-based polymer industry and, currently, it is worldwide available with several tradenames and increasing production facilities and industrial applications [10, 11]. In particular, PLA finds important applications as a rigid polymer in the packaging industry [12]. Even though many of the uses of PLA are for single-use applications, it has been described that PLA can also be successfully used for long-term engineering applications [13]. This polymer is obtained from starch-rich materials through a fermentation process, with high capacities to be degraded under hydrolytic or compost conditions. The worldwide consumption of PLA is estimated in $140000 \mathrm{t}$ [14], and it is expected a growth of the production capability of $0.8 \mathrm{Mt}$ up to 2020 [15]. PLA shows some properties similar to polystyrene (PS), which makes it suitable for blending with PA to provide tailored properties for uses in the packaging industry [16]. Another interesting topic related to the increasing use of polymer blends is the recycling of single-use plastics and/or disposable plastics. The separation of polymers during recycling is one of the most expensive stages, so polymers blending is an interesting solution. However, the lack of miscibility between materials must be taken into account. This restriction is related to miscibility, which plays a key role in obtaining high-performance polymer blends. In fact, most of the polymer blend systems are immiscible (or with very restricted miscibility) from a thermodynamic standpoint, which is highly affected by dipole-dipole, ion-dipole, hydrogen bonds, acid-base interactions, among others [17].

To overcome this drawback related to miscibility, several strategies can be approached by ex-situ (nonreactive) and in situ (reactive) extrusion processes [18]. Ex-situ extrusion involves the use of a copolymer that is highly miscible with one of the components in the blend. This process consists of a twostage process that increases overall costs so that it is only used in such applications in which the cost is not a restriction [19]. On the contrary, in situ compatibilization (reactive extrusion) is much more attractive as it can be obtained by using polymers, oligomers, and additives with highly reactive groups such as anhydride, epoxy, and isocyanate, among others. These compatibilizers can react during the extrusion process in the melt state to minimize the effects of immiscibility by reacting with hydroxyl, carboxyl, amine, and so on, groups that are typically present in condensation polymers [20].

In the last decade, vegetable oils (VOs) have gained considerable interest as bio-based building blocks for the polymer industry. Also, the particular chemical structure of unsaturated fatty acids, with one or more carbon-carbon unsaturations, allows a wide variety of chemical modifications that increase their reactive and, subsequently, their possibilities. Vegetable oils can be functionalized by acrylation [21], epoxidation [22-24], or maleinization [25], among others, with the main aim of increasing their reactivity which can be used for different purposes. Maleinized linseed oil (MLO) and epoxidized linseed oil (ELO) have been successfully used as reactive compatibilizers in different binary systems [26-28]. On the other hand, condensation polymers such as aliphatic polyesters and PAs are highly sensitive to hydrolytic degradation. Therefore, these polymers usually 
require a chain extender to minimize the effects of hydrolytic degradation. Usually, these chain extenders are glycidyl methacrylate (GMA) copolymers that are commercially available with different tradenames and compositions such as Joncry $l^{\circledR}$ from BASF or Xibond ${ }^{\mathrm{TM}}$ from Polyscope. The glycidyl group is highly reactive and can react with hydroxyl or amine end-chain groups in condensation polymers during melting and extrusion [29]. This highly reactive copolymers can in-situ react to give block copolymers by reactive extrusion by the extraction of the hydrogen of an amine or carboxylic acid end-chain group of different condensation polymers to provide increased compatibility [30].

The main aim of this work is to improve the mechanical, thermal and gas barrier properties of a fully biobased PA1010 by blending with PLA as the minor component, to widen the potential use of PA1010 in the packaging industry. To overcome the expected drawbacks related to the poor miscibility between these two polymers, different highly reactive compatibilizers were proposed. On the one hand, two vegetable oil derived compatibilizers, namely maleinized linseed oil (MLO) and epoxidized linseed oil (ELO), and on the other hand, two conventional petroleumderived chain extenders, based on glycidyl methacrylate copolymers, namely Joncryl ${ }^{\circ}$ ADR 4300 and Xibond ${ }^{\mathrm{TM}} 920$.

\section{Experimental}

\subsection{Materials}

PA1010 with the tradename NP PA1010-201 was supplied by NaturePlast (Ifs, France) in the form of pellets. According to the manufacturer, this is a fully bio-based, medium-viscosity, injection-grade homopolyamide with a density of $1.05 \mathrm{~g} \cdot \mathrm{cm}^{-3}$ and a viscosity number $(V N)$ of $160 \mathrm{~cm}^{3} \cdot \mathrm{g}^{-1}$. PLA grade Ingeo $^{\text {TM }}$ Biopolymer $2003 \mathrm{D}$ was supplied by Nature Works LLC (Minnetonka, USA) in pellet form with a typical density of $1.24 \mathrm{~g} \cdot \mathrm{cm}^{-3}$ and a melt flow index of $6 \mathrm{~g} /(10 \mathrm{~min})$ measured at $210^{\circ} \mathrm{C}$.

Regarding the bio-based compatibilizers, maleinized linseed oil (MLO) with the tradename of VEOMER LIN was obtained from Vandeputte (Mouscron, Belgium). This has a viscosity of $1000 \mathrm{cP}\left(20^{\circ} \mathrm{C}\right)$ and an acid value of $105-130 \mathrm{mg} \mathrm{KOH} \mathrm{g}^{-1}$. Epoxidized linseed oil (ELO), CAS number 8016-11-3, was supplied by Traquisa S.L. (Barcelona, Spain) and was used as a biosourced compatibilizer. This epoxidized vegetable oil is characterized by a molecular weight of about $1037 \mathrm{~g} \cdot \mathrm{mol}^{-1}$, a density of $1.05-1.06 \mathrm{~g} \cdot \mathrm{cm}^{-3}$ at $20^{\circ} \mathrm{C}$ and a viscosity of $8-11 \mathrm{P}$ at $25^{\circ} \mathrm{C}$.

Regarding the petroleum-derived chain extenders/ compatibilizers, a low functionality epoxy styreneacrylic oligomer (ESAO) with the tradename of Joncryl ${ }^{\circledR}$ ADR 4300 was obtained from BASF S.A. (Barcelona, Spain) in the form of solid granules with a molecular weight $(\mathrm{MW})$ of $5500 \mathrm{~g} \cdot \mathrm{mol}^{-1}$. This copolymer shows a $T_{\mathrm{g}}$ value of $56^{\circ} \mathrm{C}$ with an epoxy equivalent weight (EEW) of $445 \mathrm{~g} \cdot \mathrm{mol}^{-1}$. The functionality $(f)$ is 5 . The manufacturer recommends a dosage comprised between $0.4-2 \mathrm{wt} \%$ for polyesters to avoid gel formation. A random styrene-glycidyl methacrylate (PS-GMA) copolymer from Polyscope (Geleen, The Netherlands) was used as a chain extender/compatibilizer in the binary blend. Xibond ${ }^{\mathrm{TM}} 920$ was kindly supplied by Polyscope. This is a typical chain extender for poly(esters) with a molecular weight $(M W)$ of $50000 \mathrm{~g} \cdot \mathrm{mol}^{-1}$ and a $T_{\mathrm{g}}$ of $95^{\circ} \mathrm{C}$. The glycidyl methacrylate (GMA) content was $20 \%$ (mol fraction). Figure 1 shows a schematic representation of all the materials used in this study.

\subsection{Manufacturing of PA1010/PLA blends}

PA1010/PLA blends were manufactured with different compositions, as summarized in Table 1. The amount of ESAO and PS-GMA was set to $2 \mathrm{phr}$ (weight parts of compatibilizer/additive per hundred weight parts of the PA1010/PLA blend) since the manufacturer recommends this chain extender in the $0.25-2.5 \mathrm{wt} \%$ range to avoid gel formation (branching and crosslinking). Regarding the linseed oil derivatives, 5 parts per hundred resin [phr] of the blend was used. This loading was selected from previous papers of the group in which, over 5-10 phr, saturation can occur [31, 32].

PLA was dried for $24 \mathrm{~h}$ at $60^{\circ} \mathrm{C}$ while PA was dried $6 \mathrm{~h}$ at $80^{\circ} \mathrm{C}$. The corresponding amounts of each component described in Table 1 were weighed and mixed in a zipper bag as pre-homogenization stage. All materials were processed by extrusion in a DSM Xplore MC 15 micro compounder at $210-215-220^{\circ} \mathrm{C}$. The pre-mixing time inside the plasticization chamber was set to $1 \mathrm{~min}$ at a rotating speed of $100 \mathrm{rpm}$. After this time, the compounded material was forced to exit the plasticization chamber and extruded through a nozzle connected to a chill-roll system to obtain a continuous film, $60 \mathrm{~mm}$ width, and $60 \mu \mathrm{m}$ thick films at $10 \mathrm{rpm}$ and a controlled force of $700 \mathrm{~N}$. 
Base polymers for blend manufacturing<smiles>CN(CCCCCCCCCCNC(=O)CCCCCCCCC(C)(C)C)C(C)(C)C</smiles>

a)<smiles>C=C(C)C(=O)OCC</smiles>

Poly(lactic acid) - PLA

Vegetable oil-derived compatibilizers<smiles>CCCCCCCCC1OC1CCCCCCCC(=O)OCC(CC)OC(=O)CCCCCCCC1OC1CC1OC1CC1OC1CC</smiles><smiles>CCCCCC1OC1CC1OC1CCCCCCCC(=O)OC</smiles>

Epoxidized linseed oil (ELO)

b)<smiles>C/C=C/C(/C=C/C(/C=C/C(CCCCCCCC(=O)OC(COC(=O)CCCCCCC/C=C/C(C)C1CC(=O)OC1=O)C1CC(=O)OC1=O)C1CC(=O)OC1=O)C(C)C(C)=O)COC(=O)CCCCCCCC1C=CC(CCCCCC)C2C(=O)OC(=O)C12</smiles>

Maleinized linseed oil (MLO)

Petroleum-derived compatibilizers<smiles>CCC(C)C(C)(C)C1CCCCC1C(C)C</smiles>

Poly(styrene-ran-glycidyl methacrylate)

c)

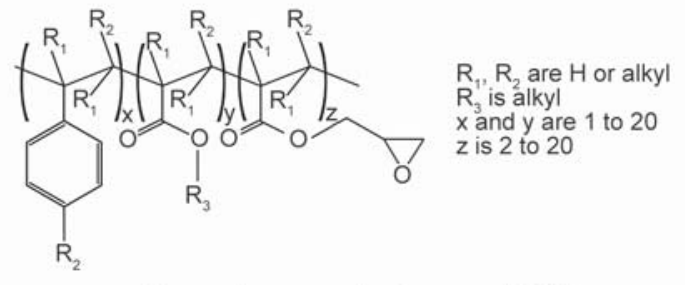

Epoxy styrene-acrylic oligomer - ESAO

Figure 1. Schematic representation of the chemical structure of base polymers, bio-based compatibilizers, and petroleumderived chain extenders/compatibilizers. a) Base polymers for blend manufacturing. b) Vegetable oil-derived compatibilizers. c) Petroleum-derived compatibilizers.

Table 1. Summary of codes and compositions according to the weight content [wt \%] of polyamide 1010 (PA1010) and polylactide (PLA) in which maleinized linseed oil (MLO), epoxidized linseed oil (ELO), epoxy-based styrene-acrylic oligomer (ESAO), and polystyrene-glycidyl methacrylate random copolymer (PS-GMA) were added as parts per hundred resin (phr) of PA1010/PLA blend.

\begin{tabular}{|c|c|c|c|c|c|c|}
\hline Code & $\begin{array}{c}\text { PA1010 } \\
\text { [wt \%] }\end{array}$ & $\begin{array}{c}\text { PLA } \\
{[w t \%]}\end{array}$ & $\begin{array}{l}\text { MLO } \\
\text { [phr] }^{*}\end{array}$ & $\begin{array}{l}\text { ELO } \\
\text { [phr] }^{*}\end{array}$ & 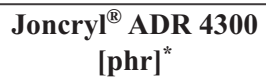 & $\begin{array}{c}\text { Xibond }^{\mathrm{TM}} 920 \\
{\text { [phr }]^{*}}^{*}\end{array}$ \\
\hline PA1010 & 100 & 0 & 0 & 0 & 0 & 0 \\
\hline PA1010/PLA & 80 & 20 & 0 & 0 & 0 & 0 \\
\hline PA1010/PLA + MLO & 80 & 20 & 5 & 0 & 0 & 0 \\
\hline PA1010/PLA + ELO & 80 & 20 & 0 & 5 & 0 & 0 \\
\hline PA1010/PLA + ESAO & 80 & 20 & 0 & 0 & 2 & 0 \\
\hline PA1010/PLA + PS-GMA & 80 & 20 & 0 & 0 & 0 & 2 \\
\hline
\end{tabular}

"phr denotes the weight parts of additives per hundred parts by weight of PA1010/PLA blend. 
In addition to films, solid samples for further characterization were obtained by a coupled injection molding unit to the DSC Xplore. The extrusion process was carried out identically as above-mentioned. Nevertheless, the chill-roll unit was changed to a $10 \mathrm{ml}$ micro-injection molding unit with the corresponding transfer chamber. This allows direct injection molding of solid samples sizing $(80 \times 10 \times$ $4 \mathrm{~mm}^{3}$ ) after the mixing process in the DSM Xplore without a previous cooling stage of the extrudate and pelletization. The injection pressure cycle was set in three stages: 8 bar $-0.3 \mathrm{~s} ; 7$ bar $-0.2 \mathrm{~s}$; and the last stage 7 bar- $-5.5 \mathrm{~s}$. The temperature of the mold was kept at $35^{\circ} \mathrm{C}$.

\subsection{Mechanical characterization}

Tensile tests were carried out in a universal test machine LLOYD $30 \mathrm{~K}$ (Hampshire, England) on film samples of $100 \mathrm{~mm}$ length, $10 \mathrm{~mm}$ width, and an average thickness of $60 \mu \mathrm{m}$ following the indications of ISO 527-1:2012. The selected load cell was $500 \mathrm{~N}$, and the cross-head speed was set to $10 \mathrm{~mm} \cdot \mathrm{min}^{-1}$. Hardness values were measured using a hardness tester durometer Brevetti AFFRI - Mod. ART. 13 (Induno Olona, Italy). Ten different measures were collected from injection-molded samples sizing $80 \times 10 \times 4 \mathrm{~mm}^{3}$, according to ISO 868:2003.

Although the main aim of this work was to characterize films, some mechanical properties were obtained on injection-molded samples to evaluate some properties that cannot be tested on film samples. For this reason, toughness was studied on injectionmolded rectangular samples with dimensions of $80 \times 10 \times 4 \mathrm{~mm}^{3}$ by the Charpy impact test with a $6-\mathrm{J}$ pendulum from Metrotec S.A. (San Sebastián, Spain) on notched samples $(0.25 \mathrm{~mm}$ radius v-notch $)$, following the specifications of ISO 179-1:2010. All mechanical tests were performed at room temperature, and at least 6 different samples of each formulation in Table 1 were tested, and the most relevant parameters of each test were calculated and averaged. The average has been calculated from the 6 values obtained while the dispersion was obtained by calculating the standard deviation.

\subsection{Thermal characterization}

The main thermal transitions of uncompatibilized and compatibilized PA1010/PLA films were obtained by differential scanning calorimetry (DSC) in a Q200 calorimeter from TA Instrument (Schwerzenbach,
Switzerland). An average sample weight of $5-8 \mathrm{mg}$ was subjected to a three-stage dynamic thermal cycle as follows: first heating from 25 to $180^{\circ} \mathrm{C}$, followed by cooling to $25^{\circ} \mathrm{C}$, and second heating to $350^{\circ} \mathrm{C}$. Heating and cooling rates were all run at $10^{\circ} \mathrm{C} \cdot \mathrm{min}^{-1}$. All tests were run in a nitrogen atmosphere with a flow of $66 \mathrm{ml} \cdot \mathrm{min}^{-1}$ using standard sealed aluminium crucibles $(40 \mu 1)$. The percentage degree of crystallinity, $\% \chi_{c}$ was determined Equation (1):

$\% \chi_{\mathrm{c}}=\frac{\Delta H_{\mathrm{m}}-\Delta H_{\mathrm{cc}}}{\Delta H_{\mathrm{m}}^{0} \cdot(1-w)}$

where $\Delta H_{\mathrm{m}}\left[\mathrm{J} \cdot \mathrm{g}^{-1}\right]$ corresponds to the melting enthalpy. $\Delta H_{\mathrm{cc}}\left[\mathrm{J} \cdot \mathrm{g}^{-1}\right]$ corresponds to the cold crystallization enthalpy. $\Delta H_{\mathrm{m}}^{0}\left[\mathrm{~J} \cdot \mathrm{g}^{-1}\right]$ stands for the melting enthalpy of a theoretically fully crystalline PA1010 and PLA, that is, $244 \mathrm{~J} \cdot \mathrm{g}^{-1}$ [33] and $93 \mathrm{~J} \cdot \mathrm{g}^{-1}$ [34] respectively. $(1-w)$ represents the weight fraction of PA1010.

The thermal stability (degradation/decomposition) of PA1010/PLA films was determined by thermogravimetric analysis (TGA) in a Seiko Exstar 6300 analyzer (Tokyo, Japan). Samples with an average weight comprised between 5 and $7 \mathrm{mg}$ were placed in standard alumina crucibles of $70 \mu 1$ and subjected to a heating program from 30 to $700^{\circ} \mathrm{C}$ at a heating rate of $10^{\circ} \mathrm{C} \cdot \mathrm{min}^{-1}$ in a nitrogen atmosphere.

\subsection{Thermomechanical characterization}

Dynamic mechanical thermal analysis (DMTA) was conducted in a DMA-1 model from Mettler-Toledo S.A. (Barcelona, Spain), with a special clamp system for films working in tension mode. Film samples sizing $10 \times 5 \times 0.06 \mathrm{~mm}^{3}$ were subjected to a temperature sweep program from -100 to $150^{\circ} \mathrm{C}$ at a heating rate of $2^{\circ} \mathrm{C} \cdot \mathrm{min}^{-1}$. The initial pretension force was $0.5 \mathrm{~N}$, and the displacement amplitude was set to $6 \mu \mathrm{m}$. The selected frequency was $1 \mathrm{~Hz}$, and DMTA tests were run in triplicate to obtain reliable data.

\subsection{Morphology characterization}

The surface morphology after failure from impact tests on injection-molded samples was observed by field emission scanning electron microscopy (FESEM). The samples were first sputtered with a palladium alloy in a sputter coater EM MED20 from Leica Microsystem (Milton Keynes, United Kingdom). The analysis was carried out in a ZEISS ULTRA 55 FESEM microscope from Oxford Instruments (Abingdon, UK) using $2 \mathrm{kV}$ as the acceleration 
voltage. To evaluate the extent of the phase separation, selective extraction of PLA was applied with chloroform supplied by Sigma Aldrich (Madrid, Spain). Film samples were immersed in chloroform solution for 24 and $48 \mathrm{~h}$, and then, dried and prepared for FESEM observation. In order to see the phase separation, analysis was carried out in a FESEM, ZEISS SUPRA 25 microscope from Oxford Instruments (Abingdon, UK) using $2 \mathrm{kV}$ as the acceleration voltage. The samples were first sputtered with a palladium alloy in a sputter coater Agar Sputter Coater - Automatic from Agar Scientific Ltd (Stansted, United Kingdom). A freeware software called Image J, developed by the Laboratory for Optical and Computational Instrumentation (LOCI, University of Wisconsin) and the National Institutes of Health in Bethesda (NIH) has been used to determine the dimensions of the droplets.

\subsection{Color measurement}

Color coordinates were determined on films using a spectrophotometer CM-2300d Konica Minolta (Tokyo, Japan). Data were acquired by using the SCI 10/D65 method, while CIELAB color variables, as defined by the Commission Internationale de 1'Éclairage (CIE 1995), were used as reported in [35]. This equipment provides the $L^{*}$ (lightness), $a^{*}$ (red-green coordinate), and $b^{*}$ (yellow-blue coordinate) parameters. The color difference between the two samples $\left(\Delta E_{\mathrm{ab}}^{*}\right)$ was calculated using Equation (2):

$\Delta E_{\mathrm{ab}}^{*}=\sqrt{\Delta L^{* 2}+\Delta a^{* 2}+\Delta b^{* 2}}$

where $\Delta L^{*}$ is the difference in $L^{*}$ (lightness) between two samples (neat PA1010 film and films of PA1010/ PLA blends) while $\Delta a^{*}$ and $\Delta b^{*}$ are the differences in the $a^{*}$ (green/red) and $b^{*}$ (blue/yellow) coordinates, respectively. For each film, five readings were taken, and the average values were calculated. $\Delta E_{\mathrm{ab}}^{*}$ values indicate the intensity in the color change. $\Delta E_{\mathrm{ab}}^{*}<0.5$ means imperceptible difference in color; $0.5 \leq \Delta E_{\mathrm{ab}}^{*}<1.5$ means a slight difference; $1.5 \leq \Delta E_{\mathrm{ab}}^{*}<3.0$ stands for a noticeable difference; $3.0 \leq \Delta E_{\mathrm{ab}}^{*}<6.0$ represents a marked difference; $6.0 \leq \Delta E_{\mathrm{ab}}^{*} \leq 12.0$ an extremely marked difference, and $\Delta E_{\mathrm{ab}}^{*}>12.0$ indicates a color of a different shade.

\subsection{Oxygen transmission rate}

The oxygen transmission rate (OTR) was measured in triplicate using a Systech Instruments 8500 oxygen permeation analyzer from Metrotec S.A. (San Sebastián, Spain) at room temperature and $2.5 \mathrm{~atm}$. Films were cut into $5 \mathrm{~cm}$ diameter circles and were compressed between the upper and lower diffusion chamber. Pure oxygen (99.9\% purity) was introduced into the upper half of the sample chamber while nitrogen was injected into the lower half. A Mitutoyo digimatic micrometer model 293-832 (Illinois, USA) was used to calculate the average thickness $-h$ of the samples all around their perimeter. The thickness of the samples was between 50 and $60 \mu \mathrm{m}$.

\section{Results and discussion}

\subsection{Mechanical characterization of PA1010/PLA blends}

Table 2 summarizes the mechanical properties of PA1010/PLA films with different compatibilizers, paying particular attention to tensile properties (tensile modulus, maximum tensile strength, and elongation at break), with regard to hardness an impact strength, (Charpy test) has been studied based on standardized samples. Neat PA1010 is an engineering

Table 2. Summary of the mechanical properties of the polyamide 1010 (PA1010)/polylactide (PLA) blends processed with maleinized linseed oil (MLO), epoxidized linseed oil (ELO), epoxy-based styrene-acrylic oligomer (ESAO), and polystyrene-glycidyl methacrylate random copolymer (PS-GMA).

\begin{tabular}{|l|c|c|c|c|c|}
\hline \multicolumn{1}{|c|}{ Films } & $\begin{array}{c}\boldsymbol{E} \\
{[\mathbf{M P a}]}\end{array}$ & $\begin{array}{c}\boldsymbol{\sigma}_{\max } \\
{[\mathbf{M P a}]}\end{array}$ & $\begin{array}{c}\boldsymbol{\varepsilon}_{\mathbf{b}} \\
{[\mathbf{\%}]}\end{array}$ & Shore D hardness $^{*}$ & $\begin{array}{c}\text { Impact strength }^{*} \\
{\left[\mathbf{k J} / \mathbf{m}^{2}\right]}\end{array}$ \\
\hline PA1010 & $700 \pm 40$ & $52 \pm 5$ & $490 \pm 30$ & $70.2 \pm 0.8$ & $6.7 \pm 0.6$ \\
\hline PLA & $1900 \pm 90$ & $44 \pm 5$ & $15 \pm 3$ & $69.1 \pm 0.7$ & $1.8 \pm 0.6$ \\
\hline PA1010/PLA & $980 \pm 55$ & $50 \pm 4$ & $470 \pm 30$ & $71.4 \pm 0.5$ & $3.0 \pm 0.2$ \\
\hline PA1010/PLA+MLO & $900 \pm 25$ & $46 \pm 3$ & $550 \pm 20$ & $69.4 \pm 0.4$ & $5.7 \pm 0.6$ \\
\hline PA1010/PLA+ELO & $1240 \pm 50$ & $77 \pm 1$ & $490 \pm 18$ & $71.0 \pm 0.7$ & $3.9 \pm 0.2$ \\
\hline PA1010/PLA+ESAO & $1000 \pm 30$ & $57 \pm 2$ & $470 \pm 35$ & $74.1 \pm 0.8$ & $3.3 \pm 0.3$ \\
\hline PA1010/PLA+PS-GMA & $1060 \pm 40$ & $59 \pm 4$ & $469 \pm 34$ & $72.4 \pm 0.9$ & $3.1 \pm 0.2$ \\
\hline
\end{tabular}

*the test has been carried out on injected samples 
plastic with a modulus of $700 \mathrm{MPa}$ and a tensile strength of $52 \mathrm{MPa}$. It was also characterized by a high elongation at break of $490 \%$ in the film form. These mechanical properties are similar to other bioPAs [29]. The addition of $20 \mathrm{wt} \%$ PLA to PA 1010 produced an increase in the tensile modulus up to $980 \mathrm{MPa}$ (which represents a \% increase of $39 \%$ ). It is important to remark that PLA is stiffer than PA1010.

On the contrary, a slight decrease in cohesion-related properties can be detected. In particular, the maximum tensile stretch decreases down to $50 \mathrm{MPa}$ and the elongation at break decreases to $470 \%$. The $\%$ decrease in these two mechanical properties is less than $5 \%$. This is a very positive effect since the typical behavior of immiscible polymer blends is a remarkable decrease in cohesion-related properties such as elongation at break, tensile strength, and toughness. It is worthy to note that even these two polymers are immiscible; addition of PLA can improve some properties of PA1010. Rashmi et al. [36], reported how the addition of $20 \mathrm{wt} \%$ PA in a brittle PLA matrix gave increased elongation and stiffness, even they observed immiscibility. As we will discuss later, the more negative effect of blending PA1010 and $20 \mathrm{wt} \%$ PLA is a clear decrease in toughness. Compatibilizers can overcome or minimize these adverse effects. Both vegetable oil-derived compatibilizers give two different effects on the base PA1010/ PLA blend. The stiffness is almost the same with a tensile modulus of $900 \mathrm{MPa}$ and the tensile strength decreases by $4 \mathrm{MPa}$ which is not critical. It remains at high values of more than $45 \mathrm{MPa}$, which is unusual for an engineering plastic. On the contrary, the elongation at break increases in a dramatic way up to $550 \%$, which is indicating two potential effects of MLO: on the one hand, a plasticization effect and, on the other hand, a compatibilization effect both contributing to improved ductile properties. As it has been reported in the literature, modified vegetable oils can positively improve ductile properties in immiscible binary/ternary blends as well as in woodplastic composites with polyester-type matrices and natural fillers [25, 31]. Regarding ELO, the first thing that strikes is a remarkable increase in the tensile strength up to values above neat PA1010 (77 MPa) with a noticeable increase in elongation at break, also superior to neat PA1010 (490\%). As expected, the stiffness also increases as the tensile modulus represents the stress to strain ratio in the linear region of a tensile diagram. As the stress is in the numerator and increases in a remarkable way, compared to the denominator (elongation), the ratio increases, thus leading to a tensile modulus of $1240 \mathrm{MPa}$, the highest of the developed materials. Therefore, it is possible to hypothesize the synergistic effect of ELO on this binary blend. Xiong et al. [37], reported that the addition of epoxidized soybean oil (ESO) on a PLA matrix led to a slight decrease in stiffness but a noticeable improvement in elongation at break. In a previous work, Quiles-Carrillo et al. [27], reported the positive effect of epoxidized-acrylated vegetable oils on both the tensile strength and the elongation at break of PLA showing this synergistic effect.

Concerning the petroleum-derived chain extenders, it is worthy to note that they can also provide increased properties to the base PA1010/PLA blend. The most relevant effect of both Joncryl ${ }^{\circledR}$ ADR 4300 and Xibond ${ }^{\mathrm{TM}} 920$ was an increase in the maximum tensile strength up to values of 56.9 and $59.0 \mathrm{MPa}$, respectively, while the elongation at break remained almost invariable compared to the uncompatibilized PA1010/PLA blend with values around 468-469\%. Because of the increase in tensile strength, the stiffness was also improved up to values above $1000 \mathrm{MPa}$ for both chain extenders. So that, both petroleumderived chain extenders can also provide compatibilization to this blend as it is composed of two condensation polymers with hydroxyl groups end-chains (from carboxylic acids in PLA and amines in PA1010). Rasselet et al. [38], showed a remarkable increase in stiffness due to the improved interface between PLA and PA11 by reactive compatibilization with ESAO, showing the additional efficiency of this chain extender on blend compatibilization. In this sense, the use of chain extensors derived from petroleum, usually give good results in poly(esters) thanks to the reaction of epoxy groups with hydroxyl terminal groups in poly(esters) like PLA [39]. Concerning hardness, the addition of $20 \mathrm{wt} \%$ PLA to PA1010 gave an increase of about 1.2 Shore D units due to the stiffness of PLA compared to that of PA1010. Both MLO and ELO showed a slight plasticization effect with lower Shore D hardness values, while both ESAO and PS-GMA copolymers delivered a slight increase in Shore D values in accordance with the increase in tensile strength.

As it has been above-mentioned, mechanical properties of immiscible polymer blends are highly sensitive to cohesion-related properties such as the strength 
and the elongation at break. It is important to remark that both of them play a critical role in toughness. Neat PA1010 showed an impact-absorbed energy of $6.7 \mathrm{~kJ} \cdot \mathrm{m}^{-2}$ (on notched samples), and this was dramatically reduced down to half the initial value by blending with $20 \mathrm{wt} \%$ PLA $\left(3.0 \mathrm{~kJ} \cdot \mathrm{m}^{-2}\right)$. This is directly related to weak interface interactions between both polymers in the binary blend, which gives poor cohesion and, subsequently, the low ability for load transfer between the two base polymers in the blend. As it can be seen in Table 2, all four compatibilizers/chain extenders, resulted in materials with improved toughness with impact strength values above $3 \mathrm{~kJ} \cdot \mathrm{m}^{-2}$ for all of them. Both Joncryl ${ }^{\circledR}$ ADR 4300 and XibondC 920 show the efficiency of GMA-based copolymers/oligomers in improving tensile strength, while the impact toughness is only slightly improved. Narajan et al. [11], have reported the exceptional properties that GMA-derived copolymers can give to PLA-based materials to improve toughness.

Nevertheless, both vegetable oil-derived compatibilizers give better results in terms of improved toughness. Addition of 5 phr ELO to the base PA1010/ PLA blend produced an impact strength of almost $4 \mathrm{~kJ} \cdot \mathrm{m}^{-2}$, which is indicating the synergistic effect above-mentioned but among all values, it strikes the high impact strength MLO can provide to this blend with an absorbed-energy of $5.7 \mathrm{~kJ} \cdot \mathrm{m}^{-2}$, very close to neat PA1010. Similar findings have been reported by Garcia-Campo et al. [28], in ternary blends of PLA/ poly(e-caprolactone) (PCL)/poly(3-hydroxybutyrate) (PHB) with soybean-derived compatibilizers. On the other hand, Ferri et al. [40] reported a remarkable improvement in toughness in binary PLA/TPS blends by using MLO.

\subsection{Morphological characterization of PA1010/PLA blends}

Figure 2 gathers FESEM images taken at $5000 \times$ of neat PA 1010 and its blends with PLA with and without compatibilizers (fractured samples from Charpy impact test). Figure $2 \mathrm{a}$ shows the fracture surface of neat PA1010. It is important to remark that these images were taken from fractured samples from impact tests (notched samples), and these conditions do not allow high plastic deformation. It can be seen a very rough surface, which corresponds to a ductile polymer. Brittle polymers show a very smooth surface with micro-crack formation and coalescence. In this case, this morphology could not be seen. The immiscibility between PA1010 and PLA can be clearly observed in Figure 2b with a PA1010-rich matrix with embedded PLA-rich droplet-like shapes. This is the typical island-in-the-sea morphology of an immiscible polymer blend. The smaller is the droplet size, the better are the overall properties of the obtained blends. The average diameter of the PLA-rich domains on uncompatibilized PA1010/PLA blend was $1.7 \pm 0.4 \mu \mathrm{m}$, which is a relatively small size and, consequently, the mechanical properties were not profoundly affected, as observed previously. This droplet size was obtained using Image J software, and it is an estimation of the diameter of spherical shapes (dispersed droplets) in the fractured surface, and an average value and the corresponding standard deviation were calculated. The effect of the compatibilizers is noticeably different depending on their nature. Both vegetable oil-derived compatibilizers produced a decrease in the average diameter of the embedded PLA-rich droplets. When using MLO as a reactive compatibilizer, the average size was $1.6 \pm 0.5 \mu \mathrm{m}$, which is slightly smaller than the uncompatibilized blend.

Nevertheless, ELO was the one that provided the most remarkable decrease in the droplet size to $0.9 \pm 0.4 \mu \mathrm{m}$. This is representative of an increase in compatibility between PA1010 and PLA due to the reaction of epoxy groups contained in ELO with end-chain hydroxyl groups of condensation polymers (mainly in carboxylic acid and amine groups). A similar behavior has been reported by Lin et al. [41] who reported a decreasing droplet size of the PA6 embedded droplets in a recycled polyethylene terephthalate (PET) matrix with increasing the content of the reactive compatibilizer, namely poly(ethylene octene-co-glycidyl methacrylate) (POE-coGMA), with elastomeric properties characterized by high flexibility. They attribute this phenomenon to the reaction of epoxy groups with $\mathrm{COOH}$ or $\mathrm{OH}$ groups in recycled PET [42], and $\mathrm{COOH}$ or $\mathrm{NH}_{2}$ groups in PA6 [43]. This assertion can be extended to the herein studied binary system with a PA and a polyester component.

Regarding the effect of ESAO (Joncryl ${ }^{\circledR}$ ADR 4300) and PS-GMA (Xibond ${ }^{\mathrm{TM}}$ 920), the average size of the droplets does not decrease. In fact, it increased for ESAO up to $2.1 \pm 0.8 \mu \mathrm{m}$, which indicates high size dispersion from tiny droplets to large particles. As it has been described previously, this chain extender provided a remarkable increase in tensile 


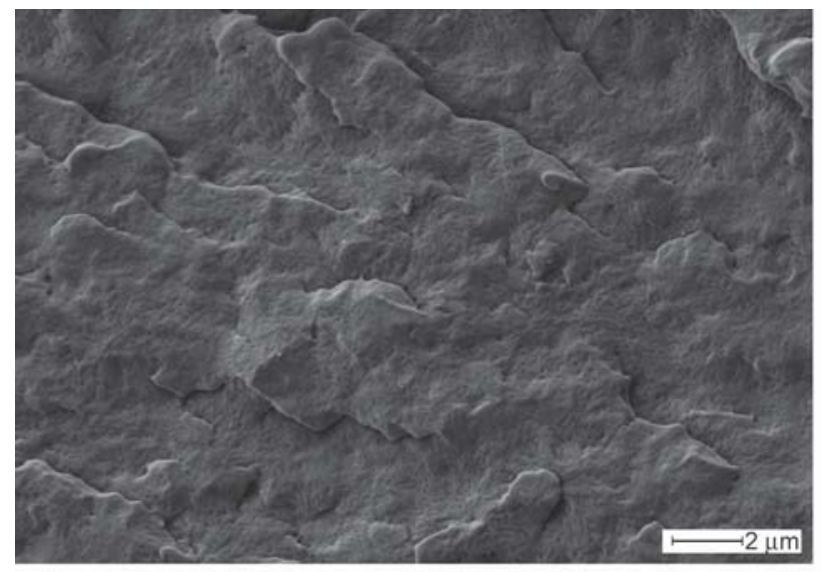

a)

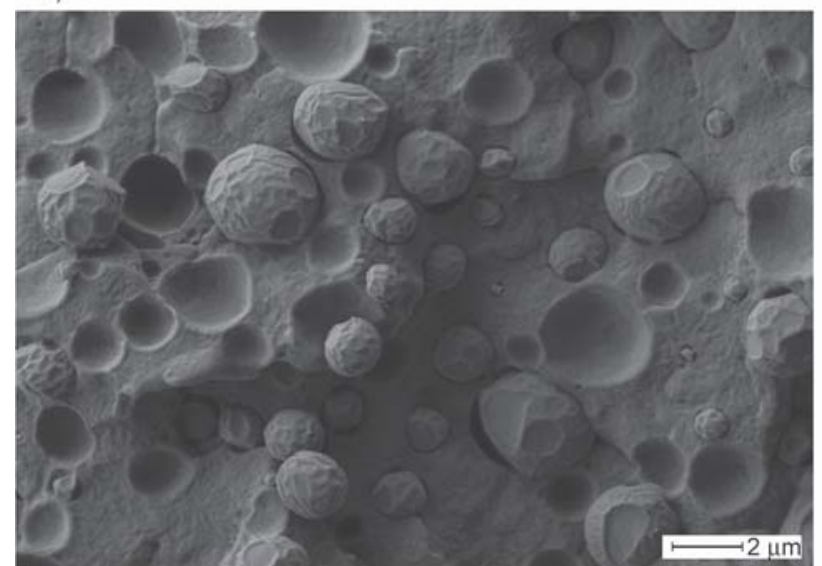

c)

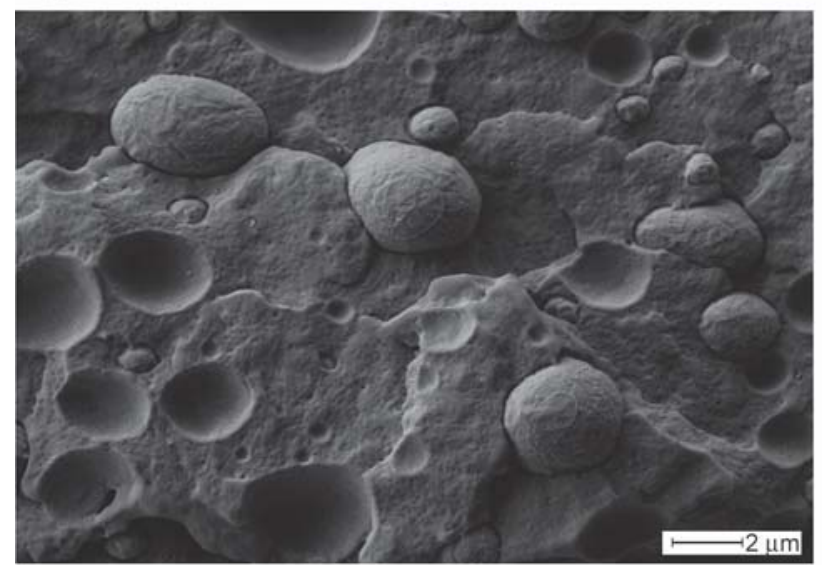

e)

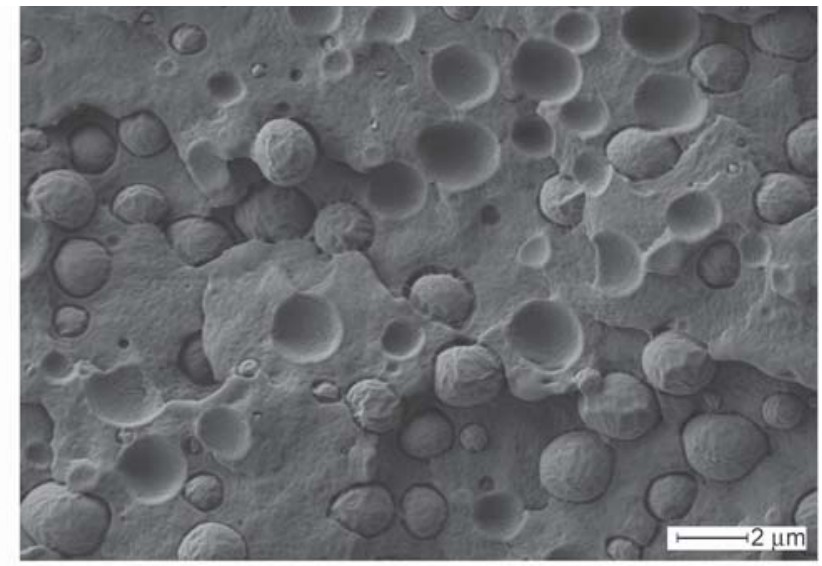

b)

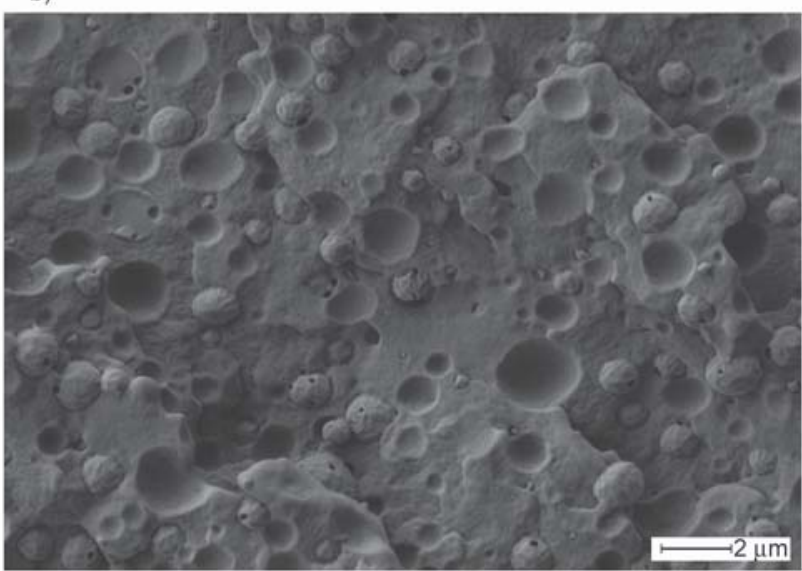

d)

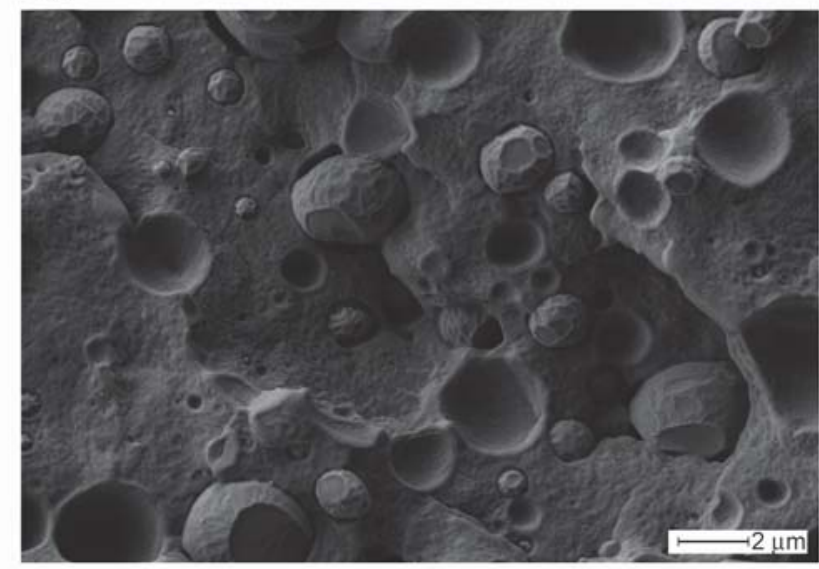

f)

Figure 2. Field emission scanning electron microscopy (FESEM) images of the fracture surfaces from the impact tests at $5000 \times$ corresponding to: a) polyamide 1010 (PA1010); b) PA1010/polylactide (PLA); c) PA1010/PLA + maleinized linseed oil (MLO); d) PA1010/PLA + epoxidized linseed oil (ELO); e) PA1010/PLA + epoxy-based styrene-acrylic oligomer (ESAO); f) polystyrene-glycidyl methacrylate random copolymer (PS-GMA).

strength, but other ductile properties were not remarkably improved. In the case of PS-GMA, the droplet size decreased to an average value of $1.7 \pm 0.7 \mu \mathrm{m}$, which is almost identical to the uncompatibilized blend but with higher size dispersion. Therefore, it is possible to expect that the main mechanism of these GMA derived compatibilizers is chain extension, as that is their primary purpose.
Both GMA derived chain extenders showed a rigid chain with high $T_{\mathrm{g}}$ values, and this probably favors chain extension instead of compatibilization.

Figure 3 shows FESEM images of the uncompatibilized PA1010/PLA blend and the corresponding images with vegetable oil-derived compatibilizers at higher magnification. As can be seen in Figure 3a, there is some intrinsic interaction between PA1010 
and PLA as the gap between the PLA-rich droplets was not homogeneous, which is representative of somewhat interactions or entanglement. Nevertheless, these interactions were much more intense in the MLO-compatibilized blend (Figure 3b) in which some filament formations surrounding the dispersed PLA-rich domains can be observed and, in general, the PLA-rich droplets seem to be more embedded in the PA1010 matrix (smaller gap size). This situation is even more pronounced in the ELO-compatibilized blend (Figure 3c) that shows an apparent decrease in the droplet size and, besides, the gap surrounding the PLA-rich droplets was almost inexistent. Anyway, it is worthy to remark that both MLO and ELO did not provide full miscibility as some voids (crater-like) can be detected in all FESEM images, which indicates some PLA-rich droplets have been pulled-out during the impact test. These images are in accordance with Walha et al. [44] that showed the reactivity (reaction rates) of the epoxy group with primary and secondary hydroxyl, carboxyl and secondary amine groups, and reported the effect of reaction of epoxy groups with both PLA and PA11 end groups, with a decrease in droplet size. They also studied the effect of a Paraloid BPMS-260 (BPMS), which is a styreneacrylic copolymer (SM) with a noticeable compatibilization effect on PLA/PA11 blends, detectable by improved interfacial adhesion between both polymers.

Despite the above-mentioned images corresponding to the impact tests of fractured injection-molded samples, they give a clear idea of the mechanical properties, both tensile and impact strength. Figure 4 gathers FESEM images of the films subjected to a selective extraction with chloroform for 2 days, as reported by Rasselet et al. [38], to selectively etch the PLA-rich nodules. The morphology is in total agreement with the previous images and gives support to the obtained mechanical properties of films. Neat PA1010 (Figure 4a) film showed a smooth surface as it was not blended. Nevertheless, the morphology of the uncompatibilized PA1010/PLA film was remarkably different, as it can be detected in Figure $4 \mathrm{~b}$. There is a preferential orientation of the PLA domains obtained after the stretching process during film formation. This preferential orientation plays a crucial role in mechanical properties; therefore, all tensile tests were carried out on film samples in the stretching, longitudinal direction. It has been widely reported the different mechanical performance of
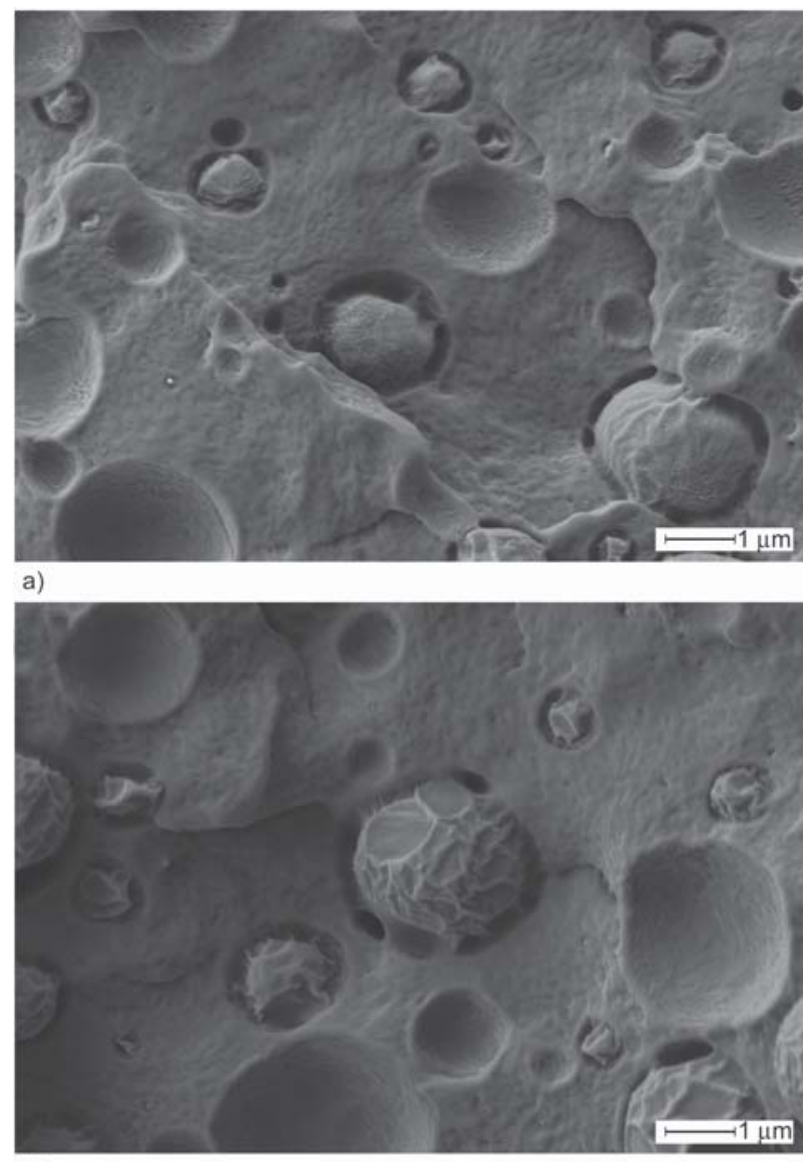

b)

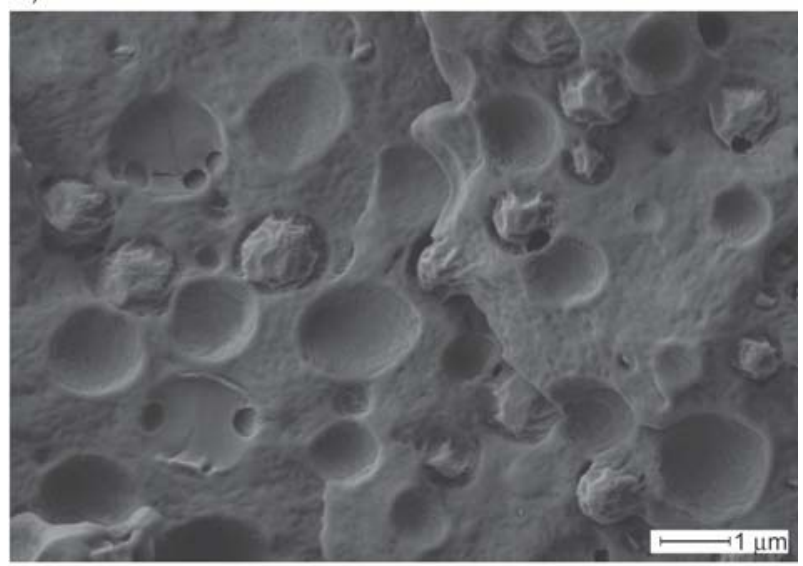

c)

Figure 3. Field emission scanning electron microscopy (FESEM) images of the fracture surfaces from impact tests at $10000 \times$ corresponding to a) polyamide $1010 \quad$ (PA1010)/polylactide (PLA; b) PA1010/PLA + maleinized linseed oil (MLO); c) PA1010/PLA + epoxidized linseed oil (ELO), showing interface phenomena between polymers.

films in the longitudinal (stretching) and perpendicular directions. In this work, the main aim was to relate the morphology of stretched films with the morphology of fractured solid samples to assess the compatibilization effect of the different compatibilizers. For this reason, mechanical properties in the transversal 

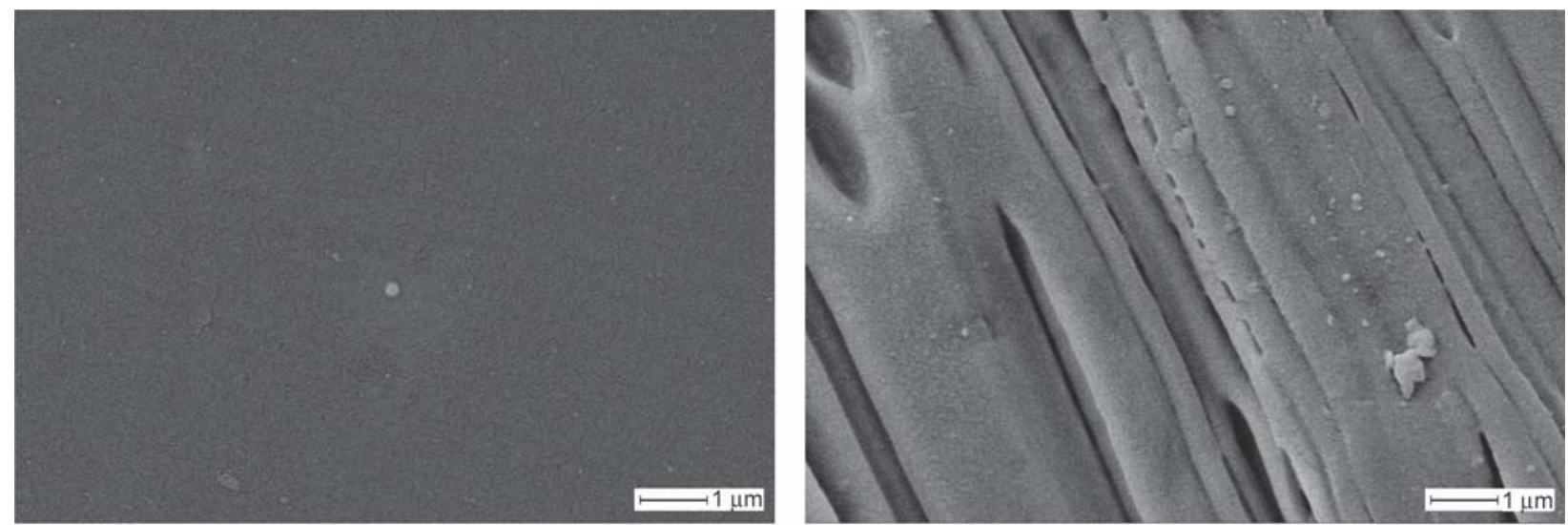

a)
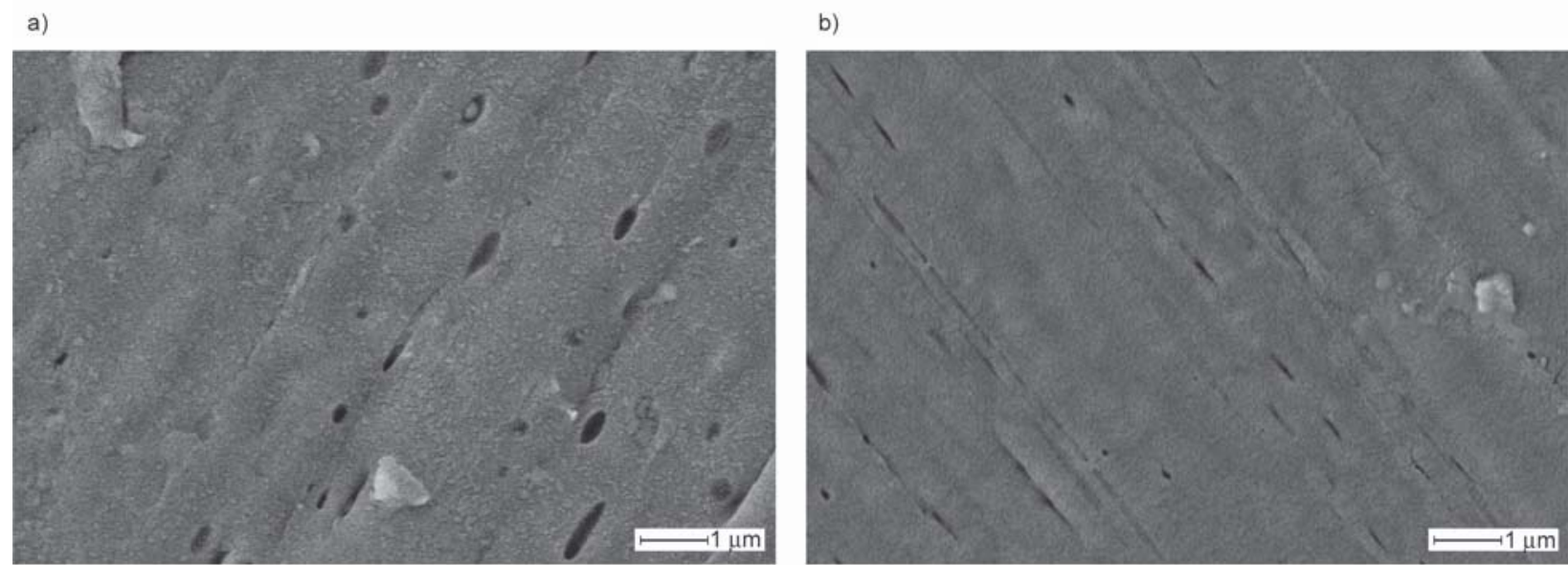

d)
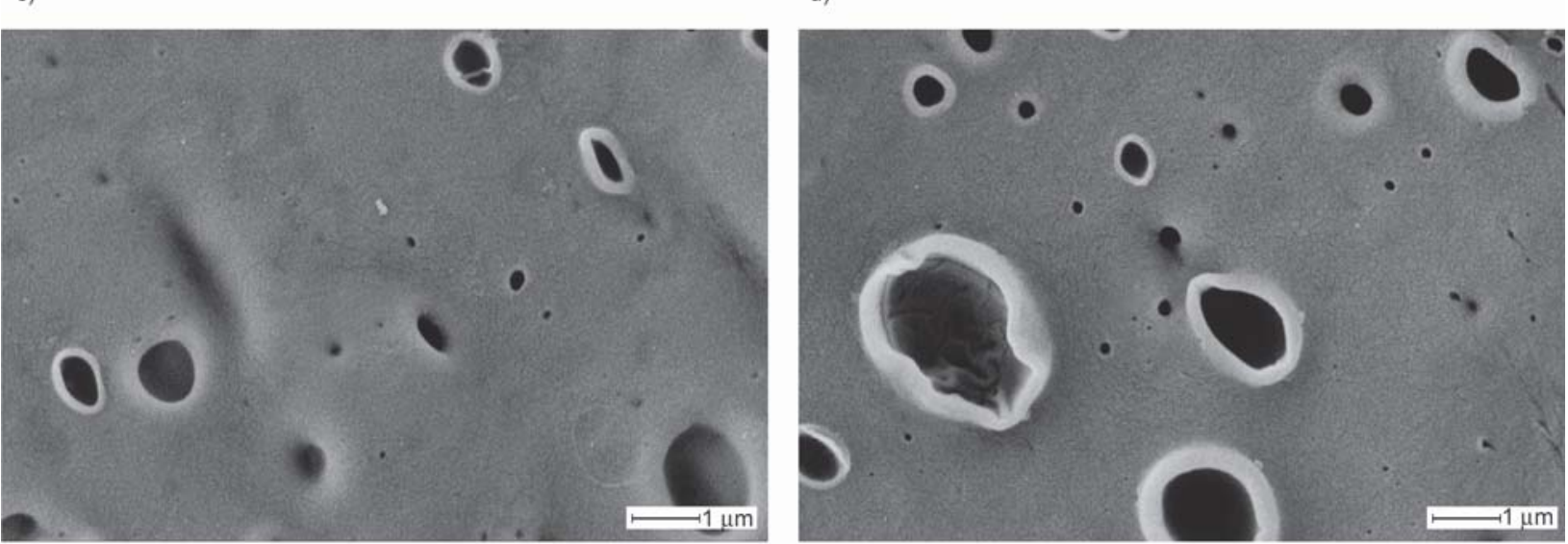

e)

f)

Figure 4. Field emission scanning electron microscopy (FESEM) images of selective etched films at $25000 \times$ corresponding to: a) polyamide 1010 (PA1010); b) PA1010/polylactide (PLA); c) PA1010/PLA + maleinized linseed oil (MLO); d) PA1010/PLA + epoxidized linseed oil (ELO); e) PA1010/PLA + epoxy-based styrene-acrylic oligomer (ESAO); f) polystyrene-glycidyl methacrylate random copolymer (PS-GMA).

(perpendicular) direction were not evaluated as these FESEM images were in accordance with the comments on the morphology of fractured solid samples, in terms of compatibilization. So that, instead of spherical PLA-rich domains, these appeared as longitudinal voids with a length of 6 to $10 \mu \mathrm{m}$. This is giving clear evidence of phase separation, and despite the morphology is remarkably different from that in
Figure $2 b$, in the end, it is the same, but, in the film, the spherical PLA-rich droplets are stretched during film formation and rolling. This phase-separation was responsible for the slight decrease in tensile strength and elongation at break, as described in Table 2 .

Concerning the vegetable oil-compatibilized blends, the first thing that strikes is that the longitudinal voids or grooves were smaller in both length and 
width, which is representative for good compatibilization. These grooves were almost undetectable in the ELO-compatibilized blend (Figure 4d), which gave improved tensile strength and enhanced elongation. In the case of MLO-compatibilized blend (Figure 4c), these grooves were detectable, but the compatibilizing effect was evident as MLO provided the highest elongation at break on PA1010/PLA films. The mechanical properties provided by both petroleum-derived compatibilizers, with increased tensile strength and negligible change in elongation (ductility), can be easily related to the FESEM images. As it can be seen in Figure 4e (ESAO-compatibilized) and Figure 4f (PS-GMA) compatibilized) in which spherical (or elliptical) PLA-rich shapes have been selectively extracted thus giving evidence of poor compatibilization. Therefore, it is expectable that the improvement in tensile strength is directly related to chain extension. As the processing conditions are different from injection-molded samples, the size of the PLA-rich droplets was smaller than that observed in the fracture surface of the injection-molded materials (see Figure 2 and Figure 3).

\subsection{Thermal properties of PA1010/PLA blends}

From a thermal standpoint, Figure 5 gathers a comparative of the DSC plots during the second heating cycle corresponding to PA1010/PLA blends with and without compatibilizers. Besides, the most relevant information from DSC characterization is gathered in Table 3. Neat PA1010 showed a double melting peak with a lower peak at $182{ }^{\circ} \mathrm{C}$ and the central peak located at $201{ }^{\circ} \mathrm{C}$. This is related to a polymorphism on crystallites, which lead to multiple melting peaks of different intensities due to the presence of different crystalline forms, i.e. $\alpha, \beta$, and $\gamma$ [45], crystal forms of packed PA1010, with different characteristic

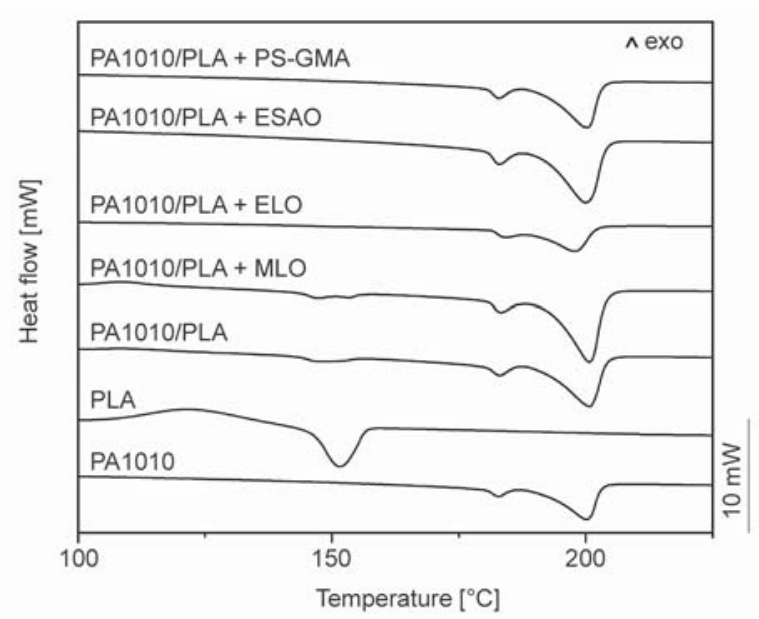

Figure 5. Differential scanning calorimetry (DSC) curves of the polyamide 1010 (PA1010)/polylactide (PLA) blends compatibilized with maleinized linseed oil (MLO), epoxidized linseed oil (ELO), epoxy-based styrene-acrylic oligomer (ESAO), and polystyreneglycidyl methacrylate random copolymer (PSGMA).

melting peaks. As it can be seen in Table 3, PLA did not affect the characteristic melting points of PA1010. This identical behavior has been observed in PA1010 blends with bio-based poly(ethylene), HDPE. Neat PLA (see Figure 5) shows a melt peak temperature of $152.3 \pm 1.2^{\circ} \mathrm{C}$. Its cold crystallization enthalpy is around $20.9 \pm 0.9 \mathrm{~J} \cdot \mathrm{g}^{-1}$, while the melt peak enthalpy is close to $21.5 \pm 0.8 \mathrm{~J} \cdot \mathrm{g}^{-1}$. These values indicate that this PLA grade shows very low crystallinity $(0.7 \% \pm 0.1)$ as the cold crystallization and the melt enthalpies ( $\Delta H_{\mathrm{cc}}$ and $\Delta H_{\mathrm{m}}$, respectively) show almost identical values. When blended with PA1010, due to the diluting effect, its specific melting point did not appear clearly in the DSC plots. Carbonell et al. [46] reported a similar thermal behavior of this PLA commercial-grade, specially intended for film manufacturing with an average melt peak temperature of $147^{\circ} \mathrm{C}$. All four compatibilizers exert a different

Table 3. Main thermal parameters of the polyamide 1010 (PA1010)/polylactide (PLA) blends compatibilized with maleinized linseed oil (MLO), epoxidized linseed oil (ELO), epoxy-based styrene-acrylic oligomer (ESAO), and polystyreneglycidyl methacrylate random copolymer (PS-GMA) in terms of: melting temperature $\left(T_{\mathrm{m}}\right)$, and normalized melting enthalpy $\left(\Delta H_{\mathrm{m}}\right)$, and degree of crystallinity $\left(\chi_{\mathrm{c}}\right)$.

\begin{tabular}{|l|c|c|c|c|}
\hline \multicolumn{1}{|c|}{ Films } & \multicolumn{1}{|c|}{$\begin{array}{c}\boldsymbol{T}_{\mathbf{m}} \\
{\left[{ }^{\circ} \mathbf{C}\right]}\end{array}$} & $\begin{array}{c}\Delta \boldsymbol{H}_{\mathbf{c c}} \\
{\left[\mathbf{J} \cdot \mathbf{g}^{-1}\right]}\end{array}$ & $\begin{array}{c}\Delta \boldsymbol{H}_{\mathbf{m}} \\
{\left[\mathbf{J} \cdot \mathbf{g}^{-1}\right]}\end{array}$ & $\begin{array}{c}\chi_{\mathbf{c}} \\
{[\%]}\end{array}$ \\
\hline PA1010 & $182.2 \pm 1.5 / 200.1 \pm 1.5$ & - & $87.3 \pm 1.1$ & $35.8 \pm 1.1$ \\
\hline PA1010/PLA & $182.5 \pm 1.5 / 200.8 \pm 1.1$ & - & $46.2 \pm 1.2$ & $23.6 \pm 1.2$ \\
\hline PA1010/PLA + MLO & $182.9 \pm 1.0 / 200.7 \pm 0.9$ & - & $46.6 \pm 1.1$ & $23.8 \pm 1.0$ \\
\hline PA1010/PLA+ELO & $183.9 \pm 0.9 / 198.1 \pm 0.8$ & - & $35.7 \pm 1.0$ & $18.3 \pm 1.0$ \\
\hline PA1010/PLA + ESAO & $182.4 \pm 0.8 / 200.0 \pm 0.7$ & - & $62.5 \pm 1.5$ & $32.0 \pm 1.4$ \\
\hline PA1010/PLA + PS-GMA & $182.6 \pm 0.7 / 200.3 \pm 0.6$ & - & $67.1 \pm 1.5$ & $34.3 \pm 1.4$ \\
\hline
\end{tabular}


effect on thermal properties and, mainly, on PA1010 crystallinity $\left(\% \chi_{c}\right)$. The thermal profile of the melting process of PA1010 remains almost invariable with all four compatibilizers. Another thing that strikes was a decrease in the degree of crystallinity in the blend from 35.8 to $23.6 \%$ in the uncompatibilized PA1010/PLA blend. Huang et al. [47], reported the critical role of the interface on crystallization by two different phenomena: crystal nucleation and crystal growth. In this case, uncompatibilized blends suggested somewhat interactions as discussed in morphology study. So, this can affect the nucleation and crystal growth. Both MLO and ELO, offer lower crystallinity values compared to neat PA1010 and ELO shows the highest decrease in crystallinity. Crystallinity is directly related to ductile properties, and both MLO and ELO showed improved elongation at break. It is worthy to note that FESEM gives clear evidence of the compatibilization effect. Nevertheless, mechanical properties are also profoundly affected by the crystallinity and, in this case, as the blends are manufactured in a film form, the rapid cooling due to the small cross-section could influence mechanical properties. As can be seen, both petroleum-derived compatibilizers led to an increase in crystallinity up to values above $32 \%$. This packed structure could be responsible for the increase in tensile strength as reported in Table 2 while the elongation at break remained invariable. Presence of ESAO and, in particular, PS-GMA favoured formation of more stable PA1010 crystals, and this has a positive effect on mechanical properties. Concerning PLA,

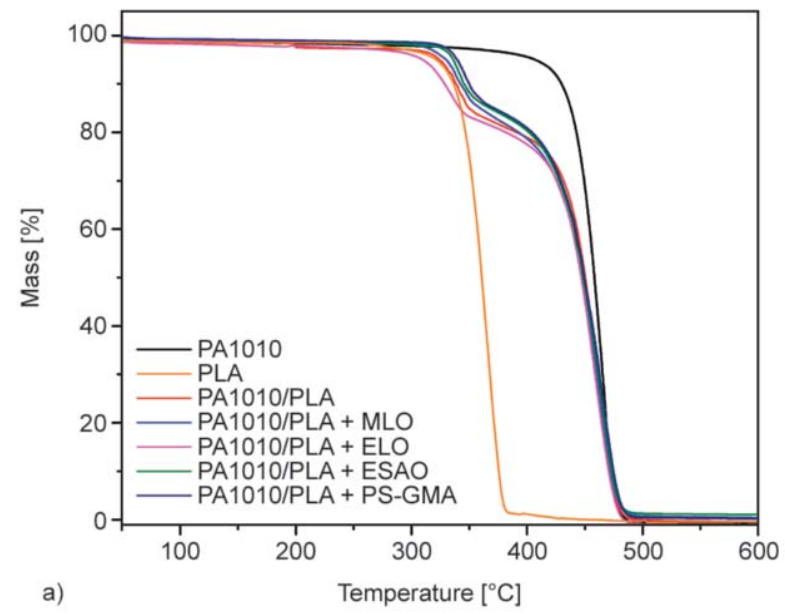

the overall crystallinity was almost disrupted, as the peak intensity is very low for ESAO- and PS-GMAcompatibilized blends. Najafi et al. [48], reported that the addition of a GMA-based chain extender on PLA led to formation of a branched structure that critically affects crystal formation. Huang et al. [47], showed the relevance of an epoxy-based compatibilizer on the crystallinity of PET/PA6 blends. They indicate that the potential reaction of the epoxy group towards $-\mathrm{COOH},-\mathrm{OH}$ and $\mathrm{NH}_{2}$ groups in both condensation polymers, could affect crystal formation with more imperfections. Therefore, this dosage for both petroleum-derived compatibilizers seems to be the optimum as recommended by the suppliers since over this, branching and crosslinking (gel formation) can occur with a negative effect on crystallinity and, subsequently, on mechanical performance. About the melting peak characteristic temperatures, ELO increased the melting peak of neat PLA by $4^{\circ} \mathrm{C}$ (and by $1.7^{\circ} \mathrm{C}$ the characteristic peak of PA1010). This effect was also previously reported by Ferri et al. [26], by the addition of MLO to a PLA matrix with an increase in the melt peak temperature of $5{ }^{\circ} \mathrm{C}$ with 5\% MLO.

TGA characterization also provided evidence of the degradation at high temperatures. Figure 6 shows a comparative plot of the characteristic TGA thermograms, while the main thermal parameters of the degradation process are summarized in Table 4. PA1010 showed excellent thermal stability. Its onset degradation temperature (taken at a weight loss of $\left.5 \%, T_{5 \%}\right)$ was $407^{\circ} \mathrm{C}$ while the maximum degradation

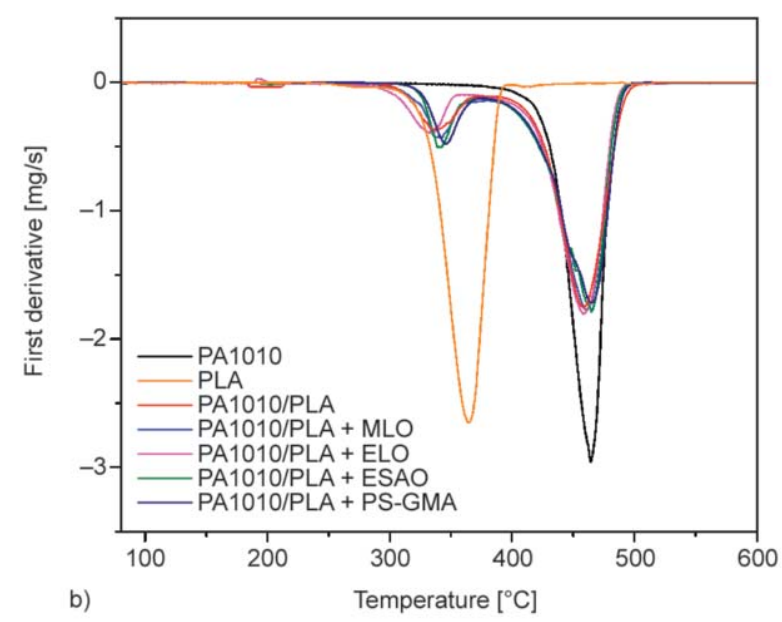

Figure 6. Thermogravimetric analysis (TGA) curves of the polyamide 1010 (PA1010)/polylactide (PLA) blends compatibilized with maleinized linseed oil (MLO), epoxidized linseed oil (ELO), epoxy-based styrene-acrylic oligomer (ESAO), and polystyrene-glycidyl methacrylate random copolymer (PS-GMA): a) \% weight loss and b) first derivative (DTG) curves. 
Table 4. Main thermal degradation parameters of the polyamide 1010 (PA1010)/polylactide (PLA) blends compatibilized with maleinized linseed oil (MLO), epoxidized linseed oil (ELO), epoxy-based styrene-acrylic oligomer (ESAO), and polystyrene-glycidyl methacrylate random copolymer (PS-GMA) in terms of: temperature at mass loss of 5\% $\left(T_{5 \%}\right)$, degradation temperature $\left(T_{\max }\right)$, and residual mass at $700^{\circ} \mathrm{C}$.

\begin{tabular}{|l|c|c|c|}
\hline \multicolumn{1}{|c|}{ Films } & $\begin{array}{c}\boldsymbol{T}_{\mathbf{5} \%} \\
{\left[{ }^{\circ} \mathbf{C}\right]}\end{array}$ & $\begin{array}{c}\boldsymbol{T}_{\max } \\
{\left[{ }^{\circ} \mathbf{C}\right]}\end{array}$ & $\begin{array}{c}\text { Residual weight } \\
{[\%]}\end{array}$ \\
\hline PA1010 & $407.2 \pm 1.2$ & $464.1 \pm 1.2$ & $0.2 \pm 0.1$ \\
\hline PLA & $320.2 \pm 0.1$ & $363.4 \pm 0.1$ & $0.1 \pm 0.1$ \\
\hline PA1010/PLA & $324.2 \pm 0.9$ & $458.4 \pm 1.3$ & $0.3 \pm 0.1$ \\
\hline PA1010/PLA+ MLO & $330.3 \pm 1.3$ & $460.9 \pm 0.9$ & $0.4 \pm 0.2$ \\
\hline PA1010/PLA+ ELO & $316.8 \pm 1.5$ & $458.5 \pm 1.0$ & $0.1 \pm 0.1$ \\
\hline PA1010/PLA+ ESAO & $336.2 \pm 1.3$ & $465.4 \pm 0.9$ & $0.7 \pm 0.2$ \\
\hline PA1010/PLA+ PS-GMA & $339.5 \pm 1.5$ & $464.8 \pm 1.1$ & $0.2 \pm 0.1$ \\
\hline
\end{tabular}

rate $\left(T_{\max }\right)$ was close to $464.1{ }^{\circ} \mathrm{C}$. Moreover, PA1010 degraded in a single step process with a residual mass of $0.2 \%$. Yang et al. [49] reported similar results for the degradation of PA1010 with an onset degradation temperature of $414^{\circ} \mathrm{C}$. The addition of $20 \mathrm{wt} \%$ to PA1010 produced a decrease in thermal stability. The onset degradation temperature moved down to $324^{\circ} \mathrm{C}$, and the maximum degradation rate temperature decreased to $458^{\circ} \mathrm{C}$, thus indicating that the main effect of PLA was on the initial degradation stages with a remarkable decrease in $T_{5 \%}$. It is also worthy to note that PLA was much more sensitive to thermal degradation than PA1010. Carbonell-Verdu et al. [46] showed a similar PLA degradation profile with an onset degradation temperature located at $321{ }^{\circ} \mathrm{C}$. Despite this low thermal stability of PLA compared to PA1010, the maximum degradation rate remained almost invariable above $450^{\circ} \mathrm{C}$. The addition of the vegetable oil derived compatibilizers did not affect significantly the compatibilized blends. In fact, $T_{5 \%}$ was almost identical for the MLO-compatibilized blend, while a decrease of $9^{\circ} \mathrm{C}$ was seen for the ELO-compatibilized blend. This decrease could be related to the plasticization that the chemically modified vegetable oils can provide to condensation polymers based on an increased free volume that could, potentially, lead to a decrease in thermal stability. Other authors have reported a decrease in the onset degradation temperatures of different polymers modified by multi-functionalized vegetable oils, namely acrylated, maleinized, and epoxidized oils [28, 31].

Concerning the effect of both petroleum-derived compatibilizers, it is worthy to note that both positively contributed to improving thermal stability. In fact, the specific $T_{5 \%}$ temperature moved up by 12 and $15^{\circ} \mathrm{C}$ for the ESAO- and PS-GMA-compatibilized blends, respectively. Concerning the degradation characteristics, $T_{\max }$ increased by $7^{\circ} \mathrm{C}$ for both compatibilizers. This improvement in thermal stability is directly linked to the internal structure obtained during the melt mixing due to the reactivity of the GMA contained in both chain extenders towards end-chain groups in both PA1010 (-COOH and $\left.\mathrm{NH}_{2}\right)$ and PLA (-COOH and $-\mathrm{OH})$. Lascano et al. [39] demonstrated that the addition of ESAO to PLA/PBSA binary blends gave a slight increase in thermal stability. Moreover, Abdelwahab et al. [50] reported that the improvement in thermal stability of PLA/PBAT blends using Joncryl ${ }^{\circledR}$ as chain extender/compatibilizer was due to an increase in the molecular weight and increased chain stiffness. Identical findings were reported by Duangphet et al. [51] for poly(3-hydroxybutyrate-co-3-hydroxyvalerate) (PHBV) with a chain extender.

\subsection{Thermomechanical properties of PA1010/PLA blends}

Figure 7 shows the evolution of dynamic-mechanical thermal analysis (DMTA) curves of neat PA1010 and the uncompatibilized and compatibilized PA1010/ PLA blends by the different compatibilizers. Table 5 contains some quantitative values of the thermomechanical properties obtained from DMTA curves. In Figure $7 \mathrm{a}$, it can be seen the evolution of the storage modulus $\left(E^{\prime}\right)$ as a function of the increasing temperature. The dynamic thermomechanical behavior of PA1010 was characterized by an $E^{\prime}$ value in the 1750 $1000 \mathrm{MPa}$ range in a wide temperature range comprised between -100 and $25^{\circ} \mathrm{C}$. Similar results can be found in the recent literature about bio-PAs [39]. Above $100^{\circ} \mathrm{C}$, the storage modulus dropped down to $177 \mathrm{MPa}$ that represents a dramatic decrease. This is directly related to the $\alpha$-relaxation process of PA1010 

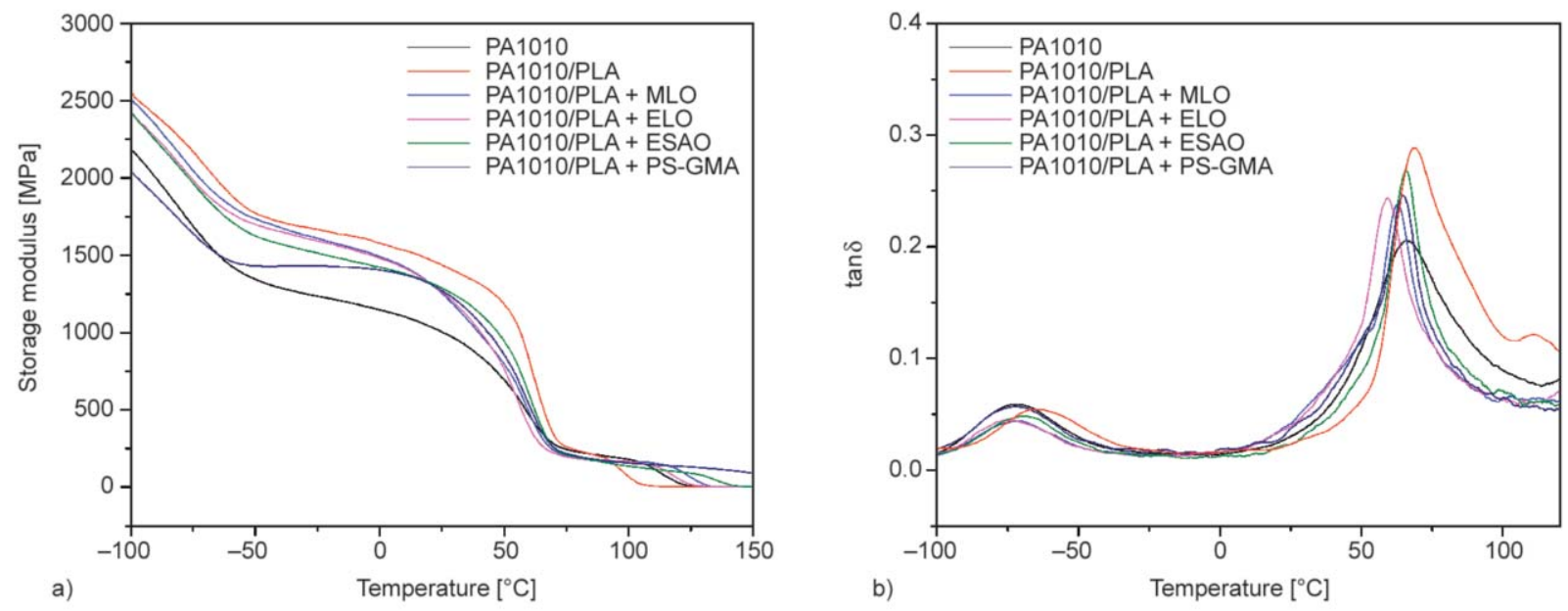

Figure 7. Dynamic mechanical thermal analysis (DMTA) curves of the polyamide 1010 (PA1010)/polylactide (PLA) blend films compatibilized with maleinized linseed oil (MLO), epoxidized linseed oil (ELO), epoxy-based styrene-acrylic oligomer (ESAO), and polystyrene-glycidyl methacrylate random copolymer (PS-GMA): a) Storage modulus, $E^{\prime}$ and b) dynamic damping factor $(\tan \delta)$.

chains in which the amorphous phase of the biopolymer changes from the glassy to rubbery state. This $\alpha$ relaxation is the most intense transition, and it is directly related to the glass transition process and its characteristic $T_{\mathrm{g}}$. The addition of $20 \mathrm{wt} \%$ PLA provided an increase in the storage modulus below $T_{\mathrm{g}}$. According to this, some authors have reported storage modulus values for PLA of $2500 \mathrm{MPa}$ at temperatures below $-40^{\circ} \mathrm{C}$ [46]. The addition of PLA enhanced the stiffness values of neat PLA. All four compatibilizers provided a slight decrease in stiffness, which can be detected by characteristic DMTA curves below that corresponding to the uncompatibilized PA1010/PLA blend. This could be related to somewhat improved

Table 5. Main thermomechanical parameters of the polyamide 1010 (PA1010)/polylactide (PLA) blend films compatibilized with maleinized linseed oil (MLO), epoxidized linseed oil (ELO), epoxy-based styrene-acrylic oligomer (ESAO), and polystyreneglycidyl methacrylate random copolymer (PSGMA) in terms of: the storage modulus ( $\left.E^{\prime}\right)$ measured at -100 and $150^{\circ} \mathrm{C}$ and the glass transition temperature $\left(T_{\mathrm{g}}\right)$.

\begin{tabular}{|l|c|r|c|}
\hline \multicolumn{1}{|c|}{ Films } & $\begin{array}{c}\boldsymbol{E}^{\prime} \text { at }-\mathbf{1 0 0}^{\circ} \mathbf{C} \\
{[\mathbf{M P a}]}\end{array}$ & $\begin{array}{c}\boldsymbol{E}^{\prime} \text { at } \mathbf{1 0 0}^{\circ} \mathbf{C} \\
{[\mathbf{M P a}]}\end{array}$ & $\begin{array}{c}\boldsymbol{T}_{\mathrm{g}}{ }^{*} \\
{\left[{ }^{\circ} \mathbf{C}\right]}\end{array}$ \\
\hline PA1010 & $2183 \pm 31$ & $177 \pm 3$ & $66.0 \pm 0.8$ \\
\hline PA1010/PLA & $2542 \pm 35$ & $59 \pm 4$ & $68.2 \pm 1.0$ \\
\hline PA1010/PLA + MLO & $2501 \pm 41$ & $164 \pm 3$ & $62.7 \pm 0.8$ \\
\hline PA1010/PLA + ELO & $2410 \pm 30$ & $167 \pm 4$ & $58.9 \pm 0.9$ \\
\hline PA1010/PLA + ESAO & $2414 \pm 27$ & $134 \pm 5$ & $65.7 \pm 1.1$ \\
\hline PA1010/PLA + PS-GMA & $2041 \pm 29$ & $156 \pm 4$ & $64.6 \pm 0.9$ \\
\hline
\end{tabular}

"The $T_{\mathrm{g}}$ was measured as the peak temperature of the $\alpha$-relaxation process related to PA1010 thorough the dynamic damping factor plots. polymer-polymer interactions, and it is in accordance with the previous observed morphology and mechanical properties. It is important to bear in mind that increased polymer-polymer interactions provide a slight increase in elongation ability due to improved stress transfer. If we consider the modulus as an estimation of the material's stiffness, the modulus shows the ratio between the applied stress and the obtained elongation. If the elongation increases while the applied stress remains almost constant, as it is in the denominator, it leads to a decrease in modulus and, subsequently, the stiffness is slightly reduced.

As can be seen in Table 5, the storage modulus changed in a remarkable way below and above $T_{\mathrm{g}}$. It is also worthy to note the effect of all the four compatibilizers on the characteristic $T_{\mathrm{g}}$ of the blends. Neat PA1010 showed a $T_{\mathrm{g}}$ of $66.0^{\circ} \mathrm{C}$, which overlaps with that of PLA, as reported by Choi et al. [52] with a $T_{\mathrm{g}}$ value of $59.1{ }^{\circ} \mathrm{C}$. As PLA is the minor component in the PA1010/PLA blends, the dilution effect did not allow to identify this $T_{\mathrm{g}}$. The $T_{\mathrm{g}}$ of the uncompatibilized PA1010/PLA blend was located at $68.2^{\circ} \mathrm{C}$, which is not a significant variation. Nevertheless, both vegetable oil-derived compatibilizers promoted a decrease in $T_{\mathrm{g}}$ to values of 62.7 and $58.9^{\circ} \mathrm{C}$, which is somewhat indicating a plasticizing effect of both MLO and ELO, as reported earlier in other polymer systems [24, 53]. It has been reported that chemically modified vegetable oils can contribute to a wide range of processes such as plasticization, compatibilization, chain extension, branching and cross-linking, but plasticization is always occurring with the use of these additives. Regarding 
the petroleum-derived compatibilizers, namely ESAO and PS-GMA, they did not provide any plasticizing effect as the $T_{\mathrm{g}}$ remained almost invariable compared to the uncompatibilized PA1010/PLA blend. Similar changes have been observed by Arruda et al. [54] in PLA/poly(butylene adipate-coterephthalate) (PBAT) blends with very slight changes in $T_{\mathrm{g}}$ in the presence of chain extenders.

\subsection{Colour measurement and visual appearance of PA1010/PLA blends}

Colour and transparency are essential factors to be considered for food packaging, as they can influence consumer perception. Figure 8 shows the visual aspect of the developed PA1010/PLA blend films meltprocessed with different compatibilizers. Initially, the addition of $20 \mathrm{wt} \%$ to PA $1010 \mathrm{did}$ not change remarkably the transparency. Some improvements in the film quality can be observed due to the disappearance of flow lines derived from PA1010 crystallization during extrusion. As one can also see, all the developed films showed high contact transparency. The biopolymer blend films were relatively transparent due to the low crystalline nature of the base polymers in the blend [55]. Some compatibilizers, namely MLO and PS-GMA, led to an increased opacity. From and end-use point of view, prevention of light penetration, especially in the ultraviolet (UV) region, could help in reducing the photo-oxidation processes of the organic compounds contained in packed food. This reduction in transparency after the addition of these compatibilizers produces films with UV-block capacity with significant potential for uses in the food packaging industry [56].

In addition to the visual inspection, the color coordinates were measured. Table 6 gathers information about transparency, $L^{*} a^{*} b^{*}$ coordinates, and color change $\left(\Delta E^{*}\right)$ for all the developed films with PA1010 and PLA with and without compatibilizers. The addition of PLA to PA1010 did not yield a significant change in the color coordinates, but transparency was reduced from 294 to 175 . The ELO-compatibilized films maintained the same transparency compared to the uncompatibilized PA1010/ PLA film (see Table 6 with then lowest $\Delta E^{*}$ values). Nevertheless, all the other three compatibilizers showed an apparent decrease in transparency with values of 140, 77, and 70 for the MLO-, PS-GMA- and ESAO-compatibilized biopolymer blend films, respectively.

Regarding color coordinates, it is important to remark that the $a^{*}$ coordinate (green to red) changed slightly to negative values (to the green) while the $b^{*}$ coordinate (blue to yellow) changed remarkably to negative values towards positive values (to the yellow), in particular for the MLO-compatibilized films [57]. These differences could be attributable to the natural color of the used additives [58]. Thus, as it has been above-mentioned regarding the visual inspection, addition of PLA and, in particular, addition of some compatibilizers led to an increased opacity and yellowing, which could be an essential restriction for applications that require extremely high transparency, but, as opposite, this same phenomenon could represent an important advantage for some applications. For example, this optical property could be desirable for some packaging materials to enhance food protection against UV light, which could cause lipid oxidation if packed food [59].

\subsection{Oxygen transmission rate of PA1010/PLA films}

One of the most critical issues related to using polymer materials in the packaging industry is the oxygen permeation. This can be easily assessed from OTR tests. This property is, sometimes, a common quality control to assess the oxygen barrier properties or to assess the potential of a polymer for packaging in controlled atmosphere conditions. Figure 9 shows the oxygen barrier properties of PA1010/PLA

Table 6. Transparency and color parameters $\left(L^{*}, a^{*}, b^{*}\right.$, and $\left.\Delta E^{*}\right)$ of the polyamide 1010 (PA1010)/polylactide (PLA) blend films compatibilized with maleinized linseed oil (MLO), epoxidized linseed oil (ELO), epoxy-based styrene-acrylic oligomer (ESAO), and polystyrene-glycidyl methacrylate random copolymer (PS-GMA).

\begin{tabular}{|l|l|c|c|c|c|}
\hline \multicolumn{1}{|c|}{ Films } & Gloss & $\boldsymbol{L}^{*}$ & $\boldsymbol{a}^{*}$ & $\boldsymbol{b}^{*}$ & $\boldsymbol{\Delta E}_{\mathbf{a b}}{ }^{*}$ \\
\hline PA1010 & G294 & $99.32 \pm 0.31$ & $-0.16 \pm 0.03$ & $0.50 \pm 0.06$ & - \\
\hline PA1010/PLA & G175 & $99.26 \pm 0.20$ & $-0.17 \pm 0.04$ & $0.38 \pm 0.05$ & $0.13 \pm 0.02$ \\
\hline PA1010/PLA + MLO & G140 & $98.41 \pm 0.23$ & $-0.74 \pm 0.02$ & $3.91 \pm 0.04$ & $3.58 \pm 0.08$ \\
\hline PA1010/PLA + ELO & G207 & $98.99 \pm 0.29$ & $-0.20 \pm 0.02$ & $0.61 \pm 0.03$ & $0.35 \pm 0.04$ \\
\hline PA1010/PLA + ESAO & G70 & $98.21 \pm 0.18$ & $-0.41 \pm 0.04$ & $2.19 \pm 0.04$ & $2.04 \pm 0.06$ \\
\hline PA1010/PLA + PS-GMA & G77 & $98.84 \pm 0.21$ & $-0.44 \pm 0.03$ & $1.72 \pm 0.06$ & $1.34 \pm 0.08$ \\
\hline
\end{tabular}



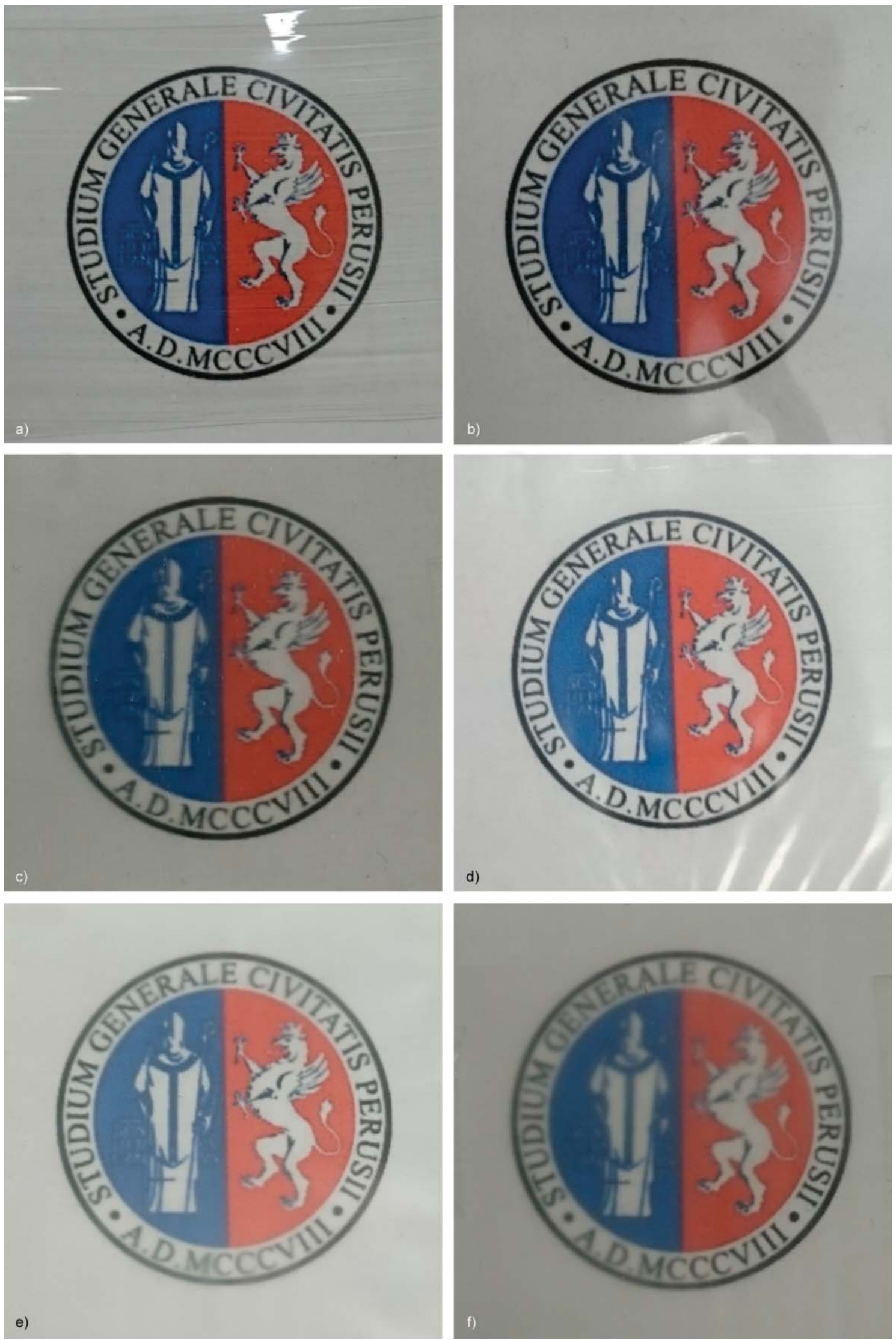

Figure 8. Visual appearance and contact transparency of films of: a) polyamide 1010 (PA1010); b) PA1010/polylactide (PLA); c) PA1010/PLA + epoxidized linseed oil (ELO); d) PA1010/PLA + epoxy-based styrene-acrylic oligomer (ESAO); f) polystyrene-glycidyl methacrylate random copolymer (PS-GMA). 


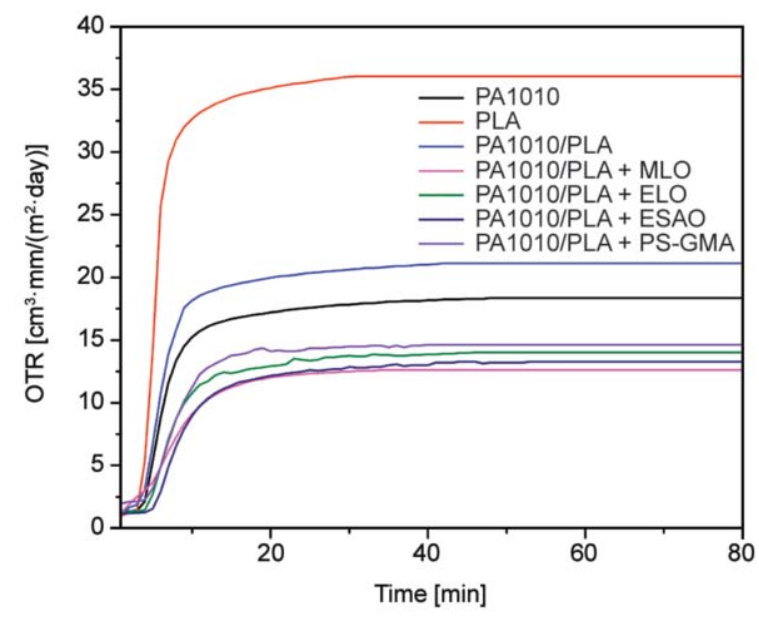

Figure 9. Oxygen transmission rate (OTR) curves of the polyamide 1010 (PA1010)/polylactide (PLA) blend films compatibilized with maleinized linseed oil (MLO), epoxidized linseed oil (ELO), epoxybased styrene-acrylic oligomer (ESAO), and polystyrene-glycidyl methacrylate random copolymer (PS-GMA) as a function of time.

blend films with different compatibilizers. Neat PA1010 showed a stabilized OTR value of $17 \mathrm{~cm}^{3} \cdot \mathrm{mm} \cdot \mathrm{m}^{-2} \cdot \mathrm{day}^{-1}$. This is a low value if compared to other PAs, such as PA6 that shows an OTR value of $55 \mathrm{~cm}^{3} \cdot \mathrm{mm} \cdot \mathrm{m}^{-2} \cdot$ day $^{-1}$ [60], which can broaden the potential use of the herein developed materials in the packaging industry.

On the other hand, it is crucial to bear in mind that PLA also offers good oxygen permeability with values about $35 \mathrm{~cm}^{3} \cdot \mathrm{mm} \cdot \mathrm{m}^{-2} \cdot$ day $^{-1}$. Arrieta et al. [61] reported an OTR value of $30.5 \mathrm{~cm}^{3} \cdot \mathrm{mm} \cdot \mathrm{m}^{-2} \cdot$ day $^{-1}$ for PLA thus, corroborating this balanced oxygen barrier properties. As expected, the addition of $20 \mathrm{wt} \%$ PLA into the PA1010 matrix led to an increase in OTR of about $20 \mathrm{~cm}^{3} \cdot \mathrm{mm} \cdot \mathrm{m}^{-2} \cdot \mathrm{day}^{-1}$. This increase is related to the poor miscibility between these two biopolymers as corroborated through this research work. All four compatibilizers interestingly provided lower OTR values of 14.6, 14, and $13.3 \mathrm{~cm}^{3} \cdot \mathrm{mm} \cdot \mathrm{m}^{-2} \cdot \mathrm{day}^{-1}$ for the PS-GMA-, ELO-, and ESAO-compatibilized films, respectively. Therefore, all four compatibilizers exerted a positive effect on the barrier properties against oxygen. It is worthy to note that the lowest OTR value was obtained for the MLO-compatibilized films with an OTR value of $12.6 \mathrm{~cm}^{3} \cdot \mathrm{mm} \cdot \mathrm{m}^{-2} \cdot \mathrm{day}^{-1}$. This could be related to a remarkable improvement in the interfacial adhesion between PA1010 and PLA (see morphology of films). Other authors have reported that using plasticizers on individual polymers can increase the free volume and, subsequently, increase the oxygen permeability [62]. Nevertheless, these compatibilizers successfully improved the barrier properties to the blend, probably due to improved interactions between these two polymers. According to this, Arrieta et al. [61] showed that the addition of cellulose nanocrystals (CNCs) into a PLA/PHB blend gave improved barrier properties due to improved interactions between both polymers thorough CNCs. The low OTR values obtained for PA1010/PLA films indicate these materials can be candidates for the packaging industry. In fact, the obtained OTR results are impressive if compared with conventional packaging materials such as PET or LDPE with OTR values of 3 and $160 \mathrm{~cm}^{3} \cdot \mathrm{mm} \cdot \mathrm{m}^{-2} \cdot \mathrm{day}^{-1}$, respectively. For these reasons, the obtained materials offer exciting properties for the industrial application in the food packaging sector [63].

\section{Conclusions}

This study reports the potential of reactive extrusion to compatibilize binary blends with engineering properties from the fully bio-based polymers PA1010 and PLA. A $20 \mathrm{wt} \%$ PLA was kept constant in the biopolymer blend formulations, and four different compatibilizers were tested. Two vegetable oil derived compatibilizers from linseed oil, namely MLO and ELO, which gave improved elongation at break and toughness, and two GMA-based additives, namely ESAO (Joncryl ${ }^{\circledR}$ ADR 4300) and PS-GMA (Xibond $^{\mathrm{TM}} 920$ ), which also provided excellent balanced properties. These materials were manufactured by cast film and injection molding, and the morphology was similar in both types of materials. Phase separation occurred, and it was more pronounced on the injection-molded materials.

Nevertheless, the vegetable oil derived compatibilizers provided a remarkable increase in elongation and toughness, and, mainly, ELO delivered an improved tensile strength. Besides, the addition of ELO produced high transparent films. Regarding the use of GMA-based additives, as well as MLO, resulted in films with improved tensile strength with a slight increase in opacity that could be helpful to protect food against UV light. Regarding the oxygen permeability, all four compatibilizers decreased OTR values compared to neat PA1010 and the uncompatibilized PA1010/PLA blend, thus giving evidence of the usefulness of all four compatibilizers to manufacture highly environmentally friendly 
films for the packaging industry without compromising the engineering properties. Depending on the final application, each compatibilizer could yield tailored properties.

\section{Acknowledgements}

This research work was funded by the Spanish Ministry of Science, Innovation, and Universities (MICIU) project numbers MAT2017-84909-C2-2-R and AGL2015-63855-C2-1R. Quiles-Carrillo and Torres-Giner are recipients of a FPU grant (FPU15/03812) from the Spanish Ministry of Education, Culture, and Sports (MECD) and a Juan de la Cierva contract (IJCI-2016-29675) from MICIU, respectively. Microscopy services at UPV are acknowledged for their help in collecting and analyzing FESEM images. Authors thank Polyscope for kindly supplying XibondTM 920 for this study.

\section{References}

[1] Quiles-Carrillo L., Montanes N., Garcia-Garcia D., Carbonell-Verdu A., Balart R., Torres-Giner S.: Effect of different compatibilizers on injection-molded green composite pieces based on polylactide filled with almond shell flour. Composites Part B: Engineering, 147, 76-85 (2018).

https://doi.org/10.1016/j.compositesb.2018.04.017

[2] Jasinska L., Villani M., Wu J., van Es D., Klop E., Rastogi S., Koning C. E.: Novel, fully biobased semicrystalline polyamides. Macromolecules, 44, 3458-3466 (2011). https://doi.org/10.1021/ma200256v

[3] Mutlu H., Meier M. A.: Castor oil as a renewable resource for the chemical industry. European Journal of Lipid Science and Technology, 112, 10-30 (2010). https://doi.org/10.1002/ej1t.200900138

[4] Kausar A.: Polyamide 1010/polythioamide blend reinforced with graphene nanoplatelet for automotive part application. Advances in Materials Science, 17, 24-36 (2017). https://doi.org/10.1515/adms-2017-0013

[5] Quiles-Carrillo L., Montanes N., Boronat T., Balart R., Torres-Giner S.: Evaluation of the engineering performance of different bio-based aliphatic homopolyamide tubes prepared by profile extrusion. Polymer Testing, 61, 421-429 (2017). https://doi.org/10.1016/j.polymertesting.2017.06.004

[6] Lagaron J. M., Gimenez E., Catala R., Gavara R.: Mechanisms of moisture sorption in barrier polymers used in food packaging: Amorphous polyamide vs. high-barrier ethylene-vinyl alcohol copolymer studied by vibrational spectroscopy. Macromolecular Chemistry and Physics, 204, 704-713 (2003).

https://doi.org/10.1002/macp.200390039
[7] Fenni S., Monticelli O., Conzatti L., Doufnoune R., Stagnaro P., Haddaoui N., Cavallo D.: Correlating the morphology of poly(L-lactide)/poly(butylene succinate)/graphene oxide blends nanocomposites with their crystallization behavior. Express Polymer Letters, 12, 58-70 (2018).

https://doi.org/10.3144/expresspolymlett.2018.5

[8] Haque M. M-U., Puglia D., Fortunati E., Pracella M.: Effect of reactive functionalization on properties and degradability of poly(lactic acid)/poly(vinyl acetate) nanocomposites with cellulose nanocrystals. Reactive and Functional Polymers, 110, 1-9 (2017).

https://doi.org/10.1016/j.reactfunctpolym.2016.11.003

[9] Rocha-Hoyos J. C., Llanes-Cedeño E. A., Peralta-Zurita D., Pucha-Tambo M.: Mechanical flexural characterization of composite materials with photopolymer matrix reinforced with abaca and cabuya fibers using $3 \mathrm{D}$ printing. Ingenius, 22, 100-112 (2019).

https://doi.org/10.17163/ings.n22.2019.10

[10] Tyler B., Gullotti D., Mangraviti A., Utsuki T., Brem H.: Polylactic acid (PLA) controlled delivery carriers for biomedical applications. Advanced Drug Delivery Reviews, 107, 163-175 (2016).

https://doi.org/10.1016/j.addr.2016.06.018

[11] Nagarajan V., Mohanty A. K., Misra M.: Perspective on polylactic acid (PLA) based sustainable materials for durable applications: Focus on toughness and heat resistance. ACS Sustainable Chemistry and Engineering, 4, 2899-2916 (2016).

https://doi.org/10.1021/acssuschemeng.6b00321

[12] Vasile C., Râpă M., Ştefan M., Stan M., Macavei S., Darie-Niţă R., Barbu-Tudoran L., Vodnar D., Popa E., Ştefan R.: New PLA/ZnO: Cu/Ag bionanocomposites for food packaging. Express Polymer Letters, 11, 531544 (2017).

https://doi.org/10.3144/expresspolymlett.2017.51

[13] van Wouwe P., Dusselier M., Vanleeuw E., Sels B.: Lactide synthesis and chirality control for polylactic acid production. ChemSusChem, 9, 907-921 (2016). https://doi.org/10.1002/cssc.201501695

[14] Nampoothiri K. M., Nair N. R., John R. P.: An overview of the recent developments in polylactide (PLA) research. Bioresource Technology, 101, 8493-8501 (2010). https://doi.org/10.1016/j.biortech.2010.05.092

[15] Hayat K., Hussain S., Abbas S., Farooq U., Ding B., Xia S., Jia C., Zhang X., Xia W.: Optimized microwave-assisted extraction of phenolic acids from citrus mandarin peels and evaluation of antioxidant activity in vitro. Separation and Purification Technology, 70, 63-70 (2009).

https://doi.org/10.1016/j.seppur.2009.08.012

[16] Castro-Aguirre E., Iñiguez-Franco F., Samsudin H., Fang X., Auras R.: Poly(lactic acid) - Mass production, processing, industrial applications, and end of life. Advanced Drug Delivery Reviews, 107, 333-366 (2016). https://doi.org/10.1016/j.addr.2016.03.010 
[17] Mazinani S., Darvishmanesh S., Ramazani R., van der Bruggen B.: Miscibility of polyimide blends: Physicochemical characterization of two high performance polyimide polymers. Reactive and Functional Polymers, 111, 88-101 (2017).

https://doi.org/10.1016/j.reactfunctpolym.2016.12.010

[18] Muthuraj R., Misra M., Mohanty A. K.: Biodegradable compatibilized polymer blends for packaging applications: A literature review. Journal of Applied Polymer Science, 135, 45726/1-45726/35 (2017).

https://doi.org/10.1002/app.45726

[19] Wu D., Zhang Y., Yuan L., Zhang M., Zhou W.: Viscoelastic interfacial properties of compatibilized poly $(\varepsilon$ caprolactone)/polylactide blend. Journal of Polymer Science Part B: Polymer Physics, 48, 756-765 (2010). https://doi.org/10.1002/polb.21952

[20] Zeng J-B., Li K-A., Du A-K.: Compatibilization strategies in poly(lactic acid)-based blends. RSC Advances, 5, 32546-32565 (2015). https://doi.org/10.1039/C5RA01655J

[21] Quiles-Carrillo L., Duart S., Montanes N., Torres-Giner S., Balart R.: Enhancement of the mechanical and thermal properties of injection-molded polylactide parts by the addition of acrylated epoxidized soybean oil. Materials and Design, 140, 54-63 (2018).

https://doi.org/10.1016/j.matdes.2017.11.031

[22] Liu W., Qiu J., Fei M., Qiu R., Sakai E., Zhang M.: Balancing performance of epoxidized soybean oil (ESO)/ poly(lactic acid) composites: Synergistic effects of carbon nanotubes and tannic acid-induced crosslinking of ESO. Express Polymer Letters, 13, 109-112 (2019). https://doi.org/10.3144/expresspolymlett.2019.11

[23] Samper M. D., Ferri J. M., Carbonell-Verdu A., Balart R., Fenollar O.: Properties of biobased epoxy resins from epoxidized linseed oil (ELO) crosslinked with a mixture of cyclic anhydride and maleinized linseed oil. Express Polymer Letters, 13, 407-418 (2019). https://doi.org/10.3144/expresspolymlett.2019.34

[24] Carbonell-Verdu A., Garcia-Garcia D., Dominici F., Torre L., Sanchez-Nacher L., Balart R.: PLA films with improved flexibility properties by using maleinized cottonseed oil. European Polymer Journal, 91, 248-259 (2017). https://doi.org/10.1016/j.eurpolymj.2017.04.013

[25] Liminana P., Garcia-Sanoguera D., Quiles-Carrillo L., Balart R., Montanes N.: Development and characterization of environmentally friendly composites from poly(butylene succinate) (PBS) and almond shell flour with different compatibilizers. Composites Part B: Engineering, 144, 153-162 (2018).

https://doi.org/10.1016/j.compositesb.2018.02.031

[26] Ferri J. M., Garcia-Garcia D., Montanes N., Fenollar O., Balart R.: The effect of maleinized linseed oil as biobased plasticizer in poly(lactic acid)-based formulations. Polymer International, 66, 882-891 (2017).

https://doi.org/10.1002/pi.5329
[27] Quiles-Carrillo L., Montanes N., Sammon C., Balart R., Torres-Giner S.: Compatibilization of highly sustainable polylactide/almond shell flour composites by reactive extrusion with maleinized linseed oil. Industrial Crops and Products, 111, 878-888 (2018). https://doi.org/10.1016/j.indcrop.2017.10.062

[28] Garcia-Campo M. J., Quiles-Carrillo L., Masia J., ReigPerez M. J., Montanes N., Balart R.: Environmentally friendly compatibilizers from soybean oil for ternary blends of poly(lactic acid)-PLA, poly( $\varepsilon$-caprolactone)PCL and poly(3-hydroxybutyrate)-PHB. Materials, 10, 1339/1-1139/19 (2017).

https://doi.org/10.3390/ma10111339

[29] Quiles-Carrillo L., Montanes N., Lagaron J., Balart R., Torres-Giner S.: In situ compatibilization of biopolymer ternary blends by reactive extrusion with low-functionality epoxy-based styrene-acrylic oligomer. Journal of Polymers and the Environment, 27, 84-96 (2019).

https://doi.org/10.1007/s10924-018-1324-2

[30] Ojijo V., Ray S. S.: Super toughened biodegradable polylactide blends with non-linear copolymer interfacial architecture obtained via facile in-situ reactive compatibilization. Polymer, 80, 1-17 (2015).

https://doi.org/10.1016/j.polymer.2015.10.038

[31] Ferri J. M., Samper M. D., García-Sanoguera D., Reig M. J., Fenollar O., Balart R.: Plasticizing effect of biobased epoxidized fatty acid esters on mechanical and thermal properties of poly(lactic acid). Journal of Materials Science, 51, 5356-5366 (2016).

https://doi.org/10.1007/s10853-016-9838-2

[32] Garcia-Garcia D., Ferri J., Boronat T., Lopez-Martinez J., Balart R.: Processing and characterization of binary poly(hydroxybutyrate) (PHB) and poly(caprolactone) (PCL) blends with improved impact properties. Polymer Bulletin, 73, 3333-3350 (2016). https://doi.org/10.1007/s00289-016-1659-6

[33] Yan M., Yang H.: Improvement of polyamide 1010 with silica nanospheres via in situ melt polycondensation. Polymer Composites, 33, 1770-1776 (2012).

https://doi.org/10.1002/pc.22318

[34] Arrieta M. P., Samper M. D., López J., Jiménez A.: Combined effect of poly(hydroxybutyrate) and plasticizers on polylactic acid properties for film intended for food packaging. Journal of Polymers and the Environment, 22, 460-470 (2014). https://doi.org/10.1007/s10924-014-0654-y

[35] Pisello A. L., Fortunati E., Fabiani C., Mattioli S., Dominici F., Torre L., Cabeza L. F., Cotana F.: PCM for improving polyurethane-based cool roof membranes durability. Solar Energy Materials and Solar Cells, 160, 34-42 (2017). https://doi.org/10.1016/j.solmat.2016.09.036 
[36] Rashmi B. J., Prashantha K., Lacrampe M-F., Krawczak P.: Toughening of poly(lactic acid) without sacrificing stiffness and strength by melt-blending with polyamide 11 and selective localization of halloysite nanotubes. AIP Conference Proceedings, 1713, 060001/1060001/5 (2016).

https://doi.org/10.1063/1.4942284

[37] Xiong Z., Yang Y., Feng J., Zhang X., Zhang C., Tang Z., Zhu J.: Preparation and characterization of poly(lactic acid)/starch composites toughened with epoxidized soybean oil. Carbohydrate Polymers, 92, 810-816 (2013).

https://doi.org/10.1016/j.carbpol.2012.09.007

[38] Rasselet D., Caro-Bretelle A. S., Taguet A., LopezCuesta J-M.: Reactive compatibilization of PLA/PA11 blends and their application in additive manufacturing. Materials, 12, 485/1-485/18 (2019). https://oi.org/10.3390/ma12030485

[39] Lascano D., Quiles-Carrillo L., Balart R., Boronat T., Montanes N.: Toughened poly (lactic acid)-PLA formulations by binary blends with poly(butylene succinate-co-adipate)-PBSA and their shape memory behaviour. Materials, 12, 622/1-622/14 (2019). https://doi.org/10.3390/ma12040622

[40] Ferri J. M., Garcia-Garcia D., Sanchez-Nacher L., Fenollar O., Balart R.: The effect of maleinized linseed oil (MLO) on mechanical performance of poly(lactic acid)-thermoplastic starch (PLA-TPS) blends. Carbohydrate Polymers, 147, 60-68 (2016).

https://doi.org/10.1016/j.carbpol.2016.03.082

[41] Lin X., Qian Q., Xiao L., Chen Q., Huang Q., Zhang H.: Influence of reactive compatibilizer on the morphology, rheological, and mechanical properties of recycled poly (ethylene terephthalate)/polyamide 6 blends. Journal of Macromolecular Science Part B: Physics, 53, 15431552 (2014).

https://doi.org/10.1080/00222348.2014.946840

[42] Liu Y., Su Z., Guo W., Li B., Wu C.: Reactive compatibilization and properties of recycled poly(ethylene terephthalate)/poly(ethylene-octene) blends. Journal of Macromolecular Science Part B: Physics, 49, 615-628 (2010).

https://doi.org/10.1080/00222341003598034

[43] Wei Q., Chionna D., Pracella M.: Reactive compatibilization of PA6/LDPE blends with glycidyl methacrylate functionalized polyolefins. Macromolecular Chemistry and Physics, 206, 777-786 (2005).

https://doi.org/10.1002/macp.200400362

[44] Walha F., Lamnawar K., Maazouz A., Jaziri M.: Biosourced blends based on poly (lactic acid) and polyamide 11: Structure-properties relationships and enhancement of film blowing processability. Advances in Polymer Technology, 37, 2061-2074 (2018).

https://doi.org/10.1002/adv.21864
[45] Logakis E., Pandis C., Peoglos V., Pissis P., Stergiou C., Pionteck J., Pötschke P., Mičušík M., Omastová M.: Structure-property relationships in polyamide 6/multiwalled carbon nanotubes nanocomposites. Journal of Polymer Science Part B: Polymer Physics, 47, 764-774 (2009). https://doi.org/10.1002/polb.21681

[46] Carbonell-Verdu A., Ferri J., Dominici F., Boronat T., Sanchez-Nacher L., Balart R., Torre L.: Manufacturing and compatibilization of PLA/PBAT binary blends by cottonseed oil-based derivatives. Express Polymer Letters, 12, 808-823 (2018).

https://doi.org/10.3144/expresspolymlett.2018.69

[47] Huang Y., Liu Y., Zhao C.: Morphology and properties of PET/PA-6/E-44 blends. Journal of Applied Polymer Science, 69, 1505-1515 (1998).

https://doi.org/10.1002/(SICI)10974628(19980822)69:8<1505::AID-APP4>3.0.CO;2-G

[48] Najafi N., Heuzey M., Carreau P.: Polylactide (PLA)clay nanocomposites prepared by melt compounding in the presence of a chain extender. Composites Science and Technology, 72, 608-615 (2012).

https://doi.org/10.1016/j.compscitech.2012.01.005

[49] Yang J., Dong W., Luan Y., Liu J., Liu S., Guo X., Zhao $\mathrm{X}$., Su W.: Crystallization and crosslinking of polyamide-1010 under elevated pressure. Journal of Applied Polymer Science, 83, 2522-2527 (2002). https://doi.org/10.1002/app.10193

[50] Abdelwahab M. A., Taylor S., Misra M., Mohanty A. K.: Thermo-mechanical characterization of bioblends from polylactide and poly(butylene adipate-co-terephthalate) and lignin. Macromolecular Materials and Engineering, 300, 299-311 (2015).

https://doi.org/10.1002/mame.201400241

[51] Duangphet S., Szegda D., Song J., Tarverdi K.: The effect of chain extender on poly(3-hydroxybutyrate-co3-hydroxyvalerate): Thermal degradation, crystallization, and rheological behaviours. Journal of Polymers and the Environment, 22, 1-8 (2014).

https://doi.org/10.1007/s10924-012-0568-5

[52] Choi K-M., Choi M-C., Han D-H., Park T-S., Ha C-S.: Plasticization of poly(lactic acid) (PLA) through chemical grafting of poly(ethylene glycol) (PEG) via in situ reactive blending. European Polymer Journal, 49, 23562364 (2013).

https://doi.org/10.1016/j.eurpolymj.2013.05.027

[53] Garcia-Garcia D., Ferri J. M., Montanes N., LopezMartinez J., Balart R.: Plasticization effects of epoxidized vegetable oils on mechanical properties of poly (3-hydroxybutyrate). Polymer International, 65, 11571164 (2016).

https://doi.org/10.1002/pi.5164 
[54] Arruda L. C., Magaton M., Bretas R. E. S., Ueki M. M.: Influence of chain extender on mechanical, thermal and morphological properties of blown films of PLA/PBAT blends. Polymer Testing, 43, 27-37 (2015).

https://doi.org/10.1016/j.polymertesting.2015.02.005

[55] Liu Z., Yan D.: Non-isothermal crystallization kinetics of polyamide 1010/montmorillonite nanocomposite. Polymer Engineering and Science, 44, 861-867 (2004). https://doi.org/10.1002/pen.20077

[56] Lasprilla-Botero J., Torres-Giner S., Pardo-Figuerez M., Álvarez-Láinez M., Lagaron J. M.: Superhydrophobic bilayer coating based on annealed electrospun ultrathin poly( $\varepsilon$-caprolactone) fibers and electrosprayed nanostructured silica microparticles for easy emptying packaging applications. Coatings, 8, 173/1-173/15 (2018). https://doi.org/10.3390/coatings8050173

[57] Fenollar O., García D., Sánchez L., López J., Balart R.: Optimization of the curing conditions of PVC plastisols based on the use of an epoxidized fatty acid ester plasticizer. European Polymer Journal, 45, 2674-2684 (2009). https://doi.org/10.1016/j.eurpolymj.2009.05.029

[58] Ramos M., Jiménez A., Peltzer M., Garrigós M. C.: Development of novel nano-biocomposite antioxidant films based on poly (lactic acid) and thymol for active packaging. Food Chemistry, 162, 149-155 (2014). https://doi.org/10.1016/j.foodchem.2014.04.026
[59] Melendez-Rodriguez B., Figueroa-Lopez K. J., Bernardos A., Martínez-Máñez R., Cabedo L., Torres-Giner S., Lagaron J. M.: Electrospun antimicrobial films of poly (3-hydroxybutyrate-co-3-hydroxyvalerate) containing eugenol essential oil encapsulated in mesoporous silica nanoparticlesles. Nanomaterials, 9, 227/1-227/23 (2019). https://doi.org/10.3390/nano9020227.

[60] Pereira D., Losada P. P., Angulo I., Greaves W., Cruz J. M.: Development of a polyamide nanocomposite for food industry: Morphological structure, processing, and properties. Polymer Composites, 30, 436-444 (2009). https://doi.org/10.1002/pc.20574

[61] Arrieta M. P., Fortunati E., Dominici F., López J., Kenny J. M.: Bionanocomposite films based on plasticized PLA-PHB/cellulose nanocrystal blends. Carbohydrate Polymers, 121, 265-275 (2015). https://doi.org/10.1016/j.carbpol.2014.12.056

[62] Martino V. P., Jiménez A., Ruseckaite R. A.: Processing and characterization of poly(lactic acid) films plasticized with commercial adipates. Journal of Applied Polymer Science, 112, 2010-2018 (2009). https://doi.org/10.1002/app.29784

[63] Burgos N., Martino V. P., Jiménez A.: Characterization and ageing study of poly(lactic acid) films plasticized with oligomeric lactic acid. Polymer Degradation and Stability, 98, 651-658 (2013). https://doi.org/10.1016/j.polymdegradstab.2012.11.009 